\title{
MOHRATÉ UNE SAINTE COPTE OUBLIÉE PAR L'HISTOIRE: SA BIOGRAPHIE ET SON ÉGLISE
}

De nos jours, plusieurs familles coptes appellent leurs filles Mohraté( $^{(1)}$ d'après le nom d'une des anciennes saintes coptes qui fut longtemps oubliée par l'histoire et dont le nom est mentionné dans les manuscrits coptes ${ }^{(2)}$ et dans le synaxaire arabe jacobite ${ }^{(3)}$ qui constitue

(1) Cette communication a été présentée durant le neuvième congrès international d'études coptes organisé par l'Association Internationale des Études Coptes de 14 à 20 septembre 2008 dans le patriarcat copte orthodoxe à 'Abbasīya au Caire. En préparant cette recherche, nous avons eu l'occasion de profiter de l'aide d'al-Qiss Yūsus Tadros al-Ḥūmī le responsable du monastère de Manīyal Šịha au Guizèh, qu'il soit chaleureusement remercié.

(2) Manuscrit Paris-arabe $n^{\circ} 73$, composé par anbā Philippe évêque de Memphis, Bibliothèque Nationale de la France, IV ${ }^{\mathrm{e}}$ siècle; Manuscrit $n^{\circ} 42$ histoire, monastère de saint Paul à la Mer Rouge, homélie de la martyre Muhrā'īl, composé par anbā Philippe évêque de Memphis, IV ${ }^{\mathrm{e}}$ siècle, f. 71 ; Manuscrit $n^{\circ}$ 93/1a histoire des patriarches de l'église copte de Sawiros ibn al-Muqaffa;, traduit de l'éthiopien à l'arabe par AKHRUSTOZOLOS ('ABD AL-MASIH), Musée Copte du Caire, XIII ${ }^{\mathrm{e}}$ siècle; Manuscrit $n^{\circ}$ 102/485 histoire-homélie. Homélie 8. Témoignage d'Abba Yassā et Thècle. Histoire (23 ba'ūna 1266 ère des martyrs/1550); Manuscrit $n^{\circ} 64$ général (64 saints), ridigé par la main d'AL-QISS DAWUD à Hārit al-Rūmm, monastère de saint Paul, 1420 ère des martyrs/1704; Manuscrit $n^{\circ} 30$ général (30 saints) ridigé par BOUTROS IBN 'ABD AL-MASIḤ, monastère de saint Paul, 1429 ère des martyrs/1713, $\mathrm{f}^{\text {os }}$. 71-126; Manuscrit $n^{\circ}$ 220/155a rite-synaxaire, au Musée Copte du Caire (1450 ère des martyrs/1734); Manuscrit $n^{\circ} 77$ histoire (103 ancien), monastère de saint Antoine, 1474 ère des martyrs/1758, fos. 168-191; Manuscrit arabe $n^{\circ} 24$ histoire-homélie, (biographie du saint martyr Abba Hor), église de la Vierge Marie à Ḥārit Zuwaila, au Caire; Manuscrit $n^{\circ} 122$ histoire, monastère de Mār Mīnā à Fumm al-Halīğg au Caire; Manuscrit $n^{\circ} 950 / 70$ rite, patriarcat copte à Ézbékeya (30 bachons 1542 ère des martyrs/1826); Manuscrit $n^{\circ}$ 1037/69 rite, ridigé par la main de IBRAHIM ȘALIB, patriarcat copte à Ézbékeya (5 tūba 1627 ère des martyrs/1911); Manuscrit $n^{\circ} 741$ histoire, monastère de saint Macaire à la Vallée du Națūn; Manuscrit de la biographie d'Apater et sa soeur Irānī. Histoire, monastère des Syriens à la Vallée $d u$ Națūn, publié par le père ABADIR AL-SURYANI, Le Caire, 1989, f. 33; Manuscrit $n^{\circ} 28$ général/18 rite, monastère des martyrs Côme et Damien à Manīyal Šịha au Guizèh.

(3) Cette source est, extrêmement, importante grâce au nombre des saints qu'elle mentionne et dû aux divers détails, notices et indications topographiques religieux qu'elle fournit aux lecteurs. R. BASSET, "Le synaxaire arabe jacobite (rédaction 
le recueil le plus important pour les biographies des saints coptes. Afin de célèbrer sa fête, une foule considérable se rend, régulièrement, aujourd'hui au monastère de Maniel Šịha ${ }^{(1)}$ (pl. I) qui se trouve sur la rive ouest du Nil à $20 \mathrm{kms}$ du Caire et à $7 \mathrm{kms}$ au sud du gouvernorat de Guizèh en face de Ma'ādī (fig. 1), sur la route d'al-Ḥawamdīya et de Badrāšīn $^{(2)}$, entre le village de Manīyal Šịha au nord et le village de Umm Hुinān ${ }^{(3)}$ au sud. Ainsi nous mettrons en évidence, tout d'abord, les détails de la vie de cette sainte dont la mémoire resta longtemps dans l'obscurité et dans le silence. Nous donnerons, ensuite, la description de sa chapelle ou bien de sa petite église en plus de la description du monastère des saints Côme et Damien à Maniel Šịha où elle se trouve.

\section{La vie de sainte Mohraté:}

Cette sainte, anonyme et longtemps oubliée, est devenue, récemment, une des célèbres saintes coptes. Elle est connue sous plusieurs noms tels que son nom grec Eirène ${ }^{(4)} / \eta \rho \eta \vee \eta$ ou bien Ira'ī “إيرائى qui signifie paix de Dieu. Signalons, aussi, son nom copte dMd $2 P d \boldsymbol{G} \boldsymbol{I}^{(5)}$ ama Heraei/ Herai ${ }^{(1)}$ qui veut dire la force de Dieu. Il semble

copte), 3. Les mois de toubeh et d'amchir", texte arabe publié, traduit et annoté, PatrOr., XI/5, Turnhout/Belgique (1915), 14 ṭūba/19 janvier.

(1) G. ViAUd, "Pilgrimages", CoptEnc., IV, New York, 1991, p. 1973.

(2) M. G. DARESSY, "Indicateur topographique du Livre des Perles enfouies et du mystère précieux", BIFAO, III, Le Caire (1917), p. 187.

(3) Des églises coptes furent construites dans ce village en l'honneur des saints George, Jean, Théodore, les quarante martyrs et la Vierge Marie. É. AMELINEAU mentionne ce village sous le nom de Mokhonoun. Deux autres villages égyptiens portent le même nom: L'un se trouve à Minūfĩya et l'autre à Fayyoum. É. AMÉlineAU, La géographie de l'Égypte copte, Paris, 1893, p. 595; YUSUF


1998, pp. 21-22.

(4) NABIL SALIM, Abtạl mağhūlūn, coll. "Min diyārat al-abā' ”, no 11, Le Caire, 1970, p. 29.

(5) Ce nom copte est mentionné dans le dialect menf. HPdI. Cf. I Papyri Copti del Museo Egizio di Torino, Trascritti e tradotti da F. Rossi, I/5, Torino 1887, pp. 3-8, 32-41, (Papyri Copti) = F. Rossi (ed.), I Martirii di Gioore, Heraie, Epimaco e Ptolomeco con altri Frammenti, Memorie della R. Accademia delle Scienze di Torino Ser. 2, XXXVIII, Torino, 1888, pp. 63-67, note ${ }^{\circ} 2$ (Martirio di Ama 


\section{MOHRATÉ UNE SAINTE COPTE OUBLIÉE PAR L'HISTOIRE}

que ce nom copte s'est transformé, avec le temps, en Maharatî (2)/Maharaté "مَكراتى ou bien Mohraté "مهراتى". Cette sainte est, également, mentionnée dans l'ouvrage attributé, à tort, à ABU ȘALIḤ (THE ARMENIAN), sous le nom de Mahrâbil. Muhrā'1'll "مهرائيل", Muhrā'ī "مهرائى" ou bien Muhrāȳ̄ll (fig. 2/a-b) sont ses noms arabes qui dérivent, à l'origine, de son nom copte.

Selon la tradition copte orthodoxe, sainte Mohraté est née, au Guizèh. Les manuscrits nous apprennent qu'elle était la fille de l'évêque Jean (fig. 3), originaire de Sirīyaqūs à Qalyūbīya ${ }^{(5)}$, et d'une femme appelée Hilarie ou Ilarīya ${ }^{(6)}$. À propos des détails de sa vie ${ }^{(7)}$, elle a vécu au $\mathrm{IV}^{\mathrm{e}}$ siècle. Elle s'est déplaçée à Țamā avec sa famille qui était originaire de Fayyūm. Un jour, elle a prit un bateau en route pour Anșinā (Antinoë) où elle s'est présentée devant le gouverneur Gallicanus ou bien Culcien et où elle fit une belle profession de foi.

Heraei di Țamma, il giorno quarto del mese di Țobe); J. HoRN, Studien zu den Märtyrern des Nördlichen Oberägypten, Coll. Göttinger Orientforschungen 4. Reihe: Ägypten, Band 15, II. Märtyrer und Heilige des XI. Bis XIV. Oberägyptischen Gaues. Ein Beitrag zur Topographia Christiana Ägyptens, Wiesbaden, 1992, p. 88, note $\mathrm{n}^{\circ} 222$.

(1) De LaCy O’Leary, the Saints of Egypt, Amsterdam, 1937, p. 152.

(2) Cette sainte est, également, mentionnée dans l'ouvrage attributé, à tort, à $\mathrm{ABU}$ ȘALIب̣ (L'ARMENIEN) sous le nom de Mahrâbil. Cf. ABŪ ȘĀLỊ̣ (THE ARMENIAN), the Churches and Monasteries of Egypt and Some Neighbouring Countries Attributed to ABŪ ȘĀLIH (THE ARMENIAN), Translated from the Original Arabic by B. T. A. M. A. EvetTs, with Added Notes by A. J. ButLer, Oxford, 1895, f. 67 (b), pp. 197-198, note ${ }^{\circ} 4$.

(3) Art., "Tārīhn mā ahmalahu al-tārīh. Muhrā’̄il-qid̄̄sa min al-qarn al-rābi' ibnat alitnā 'ašr rabī'an”, al-Yaqaẓa, IV, Le Caire (1996), pp. 31-35.

(4) Manuscrit $n^{\circ} 42$ histoire, f. 71; ABŪ'L-MAKĀRIM, Tārīh al-kanā'is wa'l-adyura fì al-qarn al-țānī ašr al-mīlādī, attribué à tort à ABŪ ȘĀLIḤ (THE ARMENIAN), II-la Haute-Égypte, la Nubie et l'Afrique, commenté par SAMUEL AL-SIRYĀNĪ et NABīH KĀMIL DĀWŪD, Le Caire, 1984, pp. 121-123.

(5) Manuscrit $n^{\circ} 42$ histoire, f. 137; N. SALĪM, Abtạl, p. 29; YūSUF TADROS AL-ḤùMĪ,

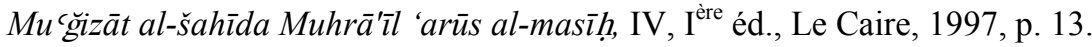

(6) N. SALĪM, Abțāl, p. 29.

(7) É. AmelineaU, Les actes des martyrs de l'église copte-étude critique, Paris, 1890, pp. 67-68, ch. 3; al-Qidīsa, pp. 16-18. 
Après qu'elle lui a récité, en plus, des réponses empruntées des Livres saints ${ }^{(1)}$, le gouverneur lui a demandé: "comment se fait-il que toi, une petite fille, tu prononces des mots graves". Elle lui a répondu: "je suis jeune d'années, je suis grande par l'esprit, comme a dit le prophète de Dieu (l'apôtre saint Paul)" (2). Dans les Actes des martyrs de l'Église Copte, É. AmelineAu affirme que Culcien était le gouverneur ou bien le $w a \bar{l} \bar{l} \mathrm{~d}$ 'Anșinā à cette époque et il ajoute que Culcien aurait remplacé Arien qui se décida à être martyr ${ }^{(3)}$. DE LACY O'LEARY signale, à son tour, que Culcianos fut le nom grec du gouverneur d'Antinoë à ce moment ${ }^{(4)}$.

Cette même histoire est, également, mentionnée dans les papyrus coptes du Muzeo Egiziano di Turino avec beaucoup plus de détails comme suit: "Accadde poi nei giorni di Colchiano, governatore di Alessandria, quando nei templi gli uomini serviano gli idoli... La beata ama Heraei chiamò le vergini sue compagne che erano venute con lei per acqua, e disse loro: sorelle mie, rallegratevi con me, voi tutte, imperocchè una grande grazia oggi ho ricevuto... Ed avendo finito di dire loro questo parole, spirò tosto un dolce vento, e navigarono solleciti verso il sud, é raggiunsero il governatore prima che approdasse alla cità di Antinoo. Rispose Heraei e disse: si, io sono piccola di corpo, ma sono grande nello spirit di Dio. Il governatore le disse: Conosci tu la lingua greca? Ella rispose: se io voglio la conosco. Disse il governatore: come hai inteso la parola che ho detto ora? Rispose Heraei: Il saggio Paolo disse: se non sapessi la virtù di chiparla con me, sarei barbaro. Per questo lo Spirito Santo dà a noi, servi di Dio, il modo di conoscere tutte le lingue. Il governatore fu presso da grande ira, ed arrossendo di mostrarsi debole innanzi a quelli che sedevano con lui, ordino che fossero tosto portati gli strumenti di tortura, e disse a lei con durezza: Heraei, sacrifica! Rispose la valorosa: Io non sacrificherò, io sono una Cristiana. Commandò che la flagellassero; ma essa parlava a Dio nel cuor suo e

(1) Manuscrit $n^{\circ}$ 220/155 rite, fos. 106-107; R. BASSET, "Synaxaire", PatrOr., XI/5, pp. 594-598, 14 țūba/19 janvier; N. SALIM, Abtạl, p. 29.

(2) R. BASSET, "Synaxaire", PatrOr., XI/5, pp. 594-598, 14 țūba/19 janvier; É. AMElineau, Actes, pp. 67-68, ch. 3, note 2.

(3) É. Amelineau, Actes, pp. 67-68, ch. 3 , note $\mathrm{n}^{\circ} 2$.

(4) De LACY O’LEARY, Saints, p. 185. 
diceva: Mio Signore, vieni a me in questa necessità; dammi forza perché io confonda quest'empio con tutti i suoi idoli fatti dalla mano dell'uomo. Ed ecco che una grande nuvola l'avvolse e sottrasse il suo corpo alla vista degli uomini. Essa gridò dicendo: arrossisci, o iniquo governatore, io non mi cruccio de' tuoi tormenti. Il governatore comandò tosto che fosse tolta di là, e fattala pore sopra un letto di ferro, ordinò che fosse sotto di esso accesso il fuoco. Ma ecco una nube d'acqua si stese sopra il letto di ferro e non lasciò che il fuoco si ascendesse, e dalla nube usci una voce che disse: Coraggio, Herai e ricevi la corona di vita, imperrochè già é preparata te una sede fra gli abitatori del cielo..."(1).

En voici la traduction: Il s'est passé sous le règne de Culcien gouverneur d'Alexandrie, quand les temples des hommes servaient les idôles. La sainte ama Heraei a appelé ses compagnons les vierges qui sont venues avec elle pour (chercher) l'eau et elle leur a dit: mes sœurs, rejouissez-vous toutes avec moi parce qu'aujourd'hui j'ai reçu une grande faveur et lorsque elle a fini de leur dire cette parole, il y a fait beau temps et elles naviguèrent rapidement vers le Sud où elle a argumenté le gouverneur immédiatement qu'elle embarca à la ville d'Antinoë. Heraei a répondu et a dit: je suis petite de corps mais je suis grande par l'Esprit de Dieu. Le gouverneur lui a dit: Connais-tu la langue grecque? Elle a répondu: je veux la connaître. Le gouverneur lui a dit: Comment a tu compris la parole que tu as dit maintenant? Heraei a répondu: Le Sage Paul a dit que si je ne sais pas la vertue de qui parle avec moi, je serai berbère. Pour cela l'Esprit Saint nous a fait, service de Dieu, le fait de connaître toutes les langues. Le gouverneur fut pris d'une grande colère et il a rougit du fait d'apparaître faible devant ceux qui étaient assis avec lui, il ordonna d'apporter tous les instruments de la torture et il a dit avec dureté: Heraei, sacrifie! La courageuse a répondu: je ne sacrifie pas, je suis chrétienne. Il commanda de la flageller; mais elle a parlé à Dieu de son cœur et elle a dit: Mon Seigneur, viens à moi dans cette nécessité. Donne-moi la force parce que je confonds ce têtu avec tous ses idôles faits des mains de l'homme. Un grand neige apparut et s'arrêta au-dessus de son corps devant la vision des hommes. Elle a crié en disant: Ô gouverneur oppresseur, je ne souffre pas de tes tempêtes. Le gouverneur commanda

(1) "Martito di Ama Heraei" et "I Martiti di Gioore, Heraei, Epimacoe Ptolomeo con Altri Frammenti”, dans: I Papyri Copti, I/5, pp. 3-8, 32-41, 63-67. 
immédiatement de l'apprendre de devant-lui, de la mettre dans un lit de fer sous lequel s'allumait le feu. Mais du brouillard, qui apparut et qui resta au-dessus du lit jusqu'à ce que le feu cessa de brûler, est sortie une voix qui a dit: Courage, Heraei et reçoit la couronne de la vie d'autant plus que t'a été préparée une place avec les habitants du ciel.

Dans un manuscrit arabe ${ }^{(1)}$, actuellement, conservé dans le Musée Copte du Caire, nous lisons, également, quelques détails de cette histoire en plus du nom arabe de Muhrā'îl et celui de Țammūh:

$$
\begin{aligned}
& \text { "اليوم الرابع عشر من شهر طوبه فى منل هذا اليوم شهادة البتول المختارة مهراييل من }
\end{aligned}
$$

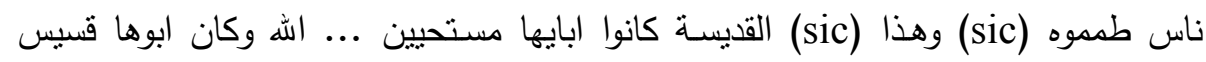



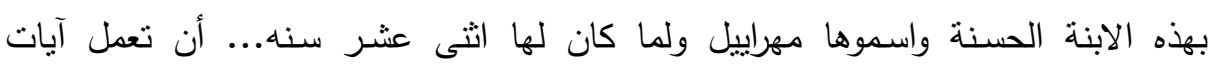

$$
\begin{aligned}
& \text { وعجايب بنعمة الروح القس الساكن فيها ... خرجت إلى طرف البحر فوجدة (sic) سفينة }
\end{aligned}
$$

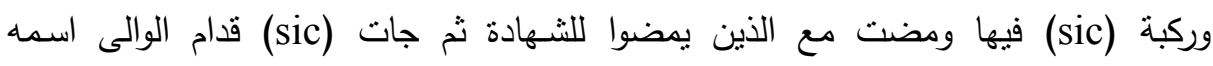

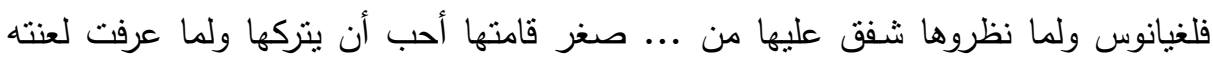

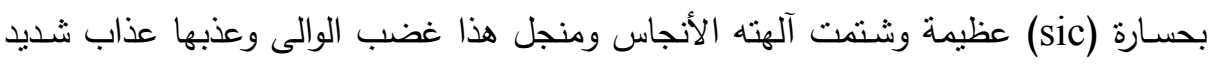

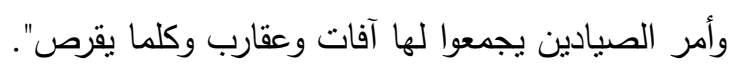

En voici la traduction: "le quatorzième jour du mois de țūba, en ce jour-ci, fut la martyre de la vierge choisie Muhrāyīl des citoyens de Ṭammūh. Son père Jean qui était prêtre et sa mère qui s'appelait Hilarie n'avaient pas d'enfants... Ils étaient tristes et ils ont prié Dieu. Après longtemps, Dieu leur a donné cette belle fille et ils l'ont appelée Muhrāyīl... Ayant douze ans, ses miracles ont apparu. Étant sortie au bord de la mer, elle trouva un bâteau où elle monta avec d'autres qui souhaitaient la martyre. Arrivée devant le wālì Flighyanos (sic) (Culcianos) qui, en la voyant, eut pitié d'elle dû à sa petite taille. Ayant décidé de la laisser, elle a insulté ses dieux. Ainsi, le gouverneur s'est fâché d'elle, il l'a sévèrement torturé et il a ordonné les chasseurs de lui ramasser les insectes, les scorpions et tout ce qui pique". Signalons que d'après ce manuscrit, Mohraté fut persécutée par les insectes et les reptiles mais dans le papyrus copte publié par F. Rossi, elle a souffert du feu.

(1) Manuscrit $n^{\circ}$ 220/155 rite -synaxaire-, fos. 106-107. 


\section{MOHRATÉ UNE SAINTE COPTE OUBLIÉE PAR L'HISTOIRE}

Ayant douze ans, Mohraté s'est martyrisée (Martyrium Sanctae Heraei) le troisième jour de son emprisonnage, c'est à dire, le 14 tūba/19 janvier $^{(1)}$ sous le règne de l'empereur romain Dioclétien en 304 ${ }^{(2)}$. La date de sa mort est, également, mentionnée dans l'ouvrage publié par F. Ross en italien comme suit: "Martirio di Ama Heraei di Tamma nel giorno decimoquarto del mese di Tobe" et en copte: "TMdPTYPId

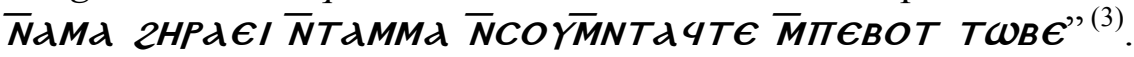

Le manuscrit, actuellement, conservé dans l'église de la Vierge Marie à Hāârit Zuwaila ${ }^{(4)}$ au Caire mentionne le nom et l'histoire de son frère abba Họor al-Siryāqūsī ${ }^{(5)}$ qui est né (le $\left.12 \mathrm{abīb}\right)^{(6)}$ trois ans après la naissance de sainte Mohraté. Il fut ainsi appelé d'après le nom de son grand père ${ }^{(7)}$. Étant prêtre à Țamă ${ }^{(8)}$ ou bien TTimā, abba Ḥor alSiryāqūsī s'est martyrisé dans l'église de ce village, au mois de tūt/18

(1) Manuscrit $n^{\circ} 42$ histoire, f. 71; ABU ȘALỊ̣ (THE ARMENIAN), Churches, pp. 197198, note n²4; De LACY O’LeARY, Saints, p. 185; N. SAlim, Abtāl, p. 29; MiCHEL FARID ĠIBRIYAL, al-Qid̄̄sa Muhrā'îl sìratuhā mawținuhā kanā'isuhāa, İ̀re éd., Le Caire, 2000, pp. 10-11.

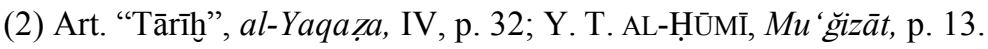

(3) I Papyri Copti, I/5, p. 4.

(4) Manuscrit $n^{\circ} 24$ histoire-homélie; YŪSUF TADROS AL-ḤŪMĪ, Sīrat wa mu ğgizāt al šahìda Muhrā'̄̄l (Maharātī), I, II éd., revisé par ANBĀ BICHOÏ, Le Caire, 2000, pp. 22-23.

(5) Son nom est, également, mentionné dans un autre manuscrit conservé dans le Musée Copte du Caire. Manuscrit $n^{\circ}$ 220/155 rite, f. 108; Y. T. AL-Ḥ̂̄MĪ, $M u$ ' $\breve{g i z a} t, 13$, pp. 22-23.

(6) Y. T. AL-ḤūMĪ, Mu' '̆izāt, p. 13.

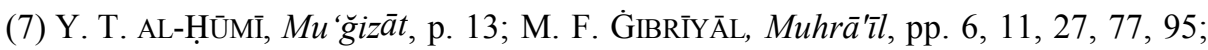
NAŠ'AT ZUQLUMA, al-Qidīsa Muhrā'̄̄l 'arūs al-ṣa 'ìd, Le Caire, 2003, p. 3.

(8) Fondée en 1844 et en 1857, cette région est devenue une des régions de Ṭahțā. Le nom copte de Tama est, parfois, écrit таммwoY. Cf. I Papiri Copti, I/5, p. 63, note $n^{\circ}$ 2; YAQUT AL-ḤAMAWI, Kitāb mu '̆gam al-buldān, Beirūt, II, 1906, p. 563; MUHAMMAD RAMZI, al-Qāmūs al-ğugrāầ li'l-bilād al-mișrīya min 'ahd almișrīyyīn ilā sanat 1945, II, Le Caire, 1994, II, p. 19, note $\mathrm{n}^{\circ}$ 5; al-Qidīsa alšahìda Maharātī šahìdat madīnat Ṭimāa-Ṭamāw bisūhāğ , I ère éd., Le Caire, 1998, p. 7 . 


\section{MOHRATÉ UNE SAINTE COPTE OUBLIÉE PAR L'HISTOIRE}

septembre $^{(1)}$, lors du carnage qui eut lieu sous le règne d'Arianus le préfet de ce village ${ }^{(2)}$. La fête de abba Ḥor al-Siryāqūsī est donc annuellement célébrée le 12 abīb/19 juillet ${ }^{(3)}$.

$\mathrm{Au} \mathrm{IV}^{\mathrm{e}}$ siècle, Philippe l'évêque de l'ancienne ville de Memphis ${ }^{(4)}$ (l'actuel Badrāšīn, Hawamdīya et Mit Rahīna) a ridigé la biographie de sainte Mohraté. Son nom Muhrā'ì "مهر ائى est, aussi, mentionné dans la première feuille du manuscrit, actuellement, conservé dans la Bibliothèque Nationale de la France à Paris ${ }^{(5)}$ (fig. 3). C'est le plus ancien manuscrit qui mentionne tous les détails de la biographie de cette sainte. Nous y lisons:

$$
\text { "هذه الثـيدة القديسـة مهرائى التىى من أهل طمويـه". }
$$

C'est à dire, "C'est la martyre la sainte Mohraté qui est des habitants de Țamwīh". Le chercheur NABIL SALIM affirme, lui-aussi, que cette sainte était originaire de Tamwīh ${ }^{(6)}$. D'après AL-ŠABUSTI, Tamwīh "طهـوه" de Memphis est un village qui se trouve au sud de Guizèh à

(1) Y. T. AL-ḤumI, Sïrat, p. 112.

(2) al-Qidīsa, p. 9.

(3) Y. T. AL-HuMI, Mu 'ğizāt, IV, p. 13; N. ZuQLUMA, Muhrā's̄l, p. 3.

(4) Le nom égyptien de cette ville est mit rhnt. En Égypte Ancienne, un triade composé du dieu Pth, de la déesse shmt, du dieu nfr tm et de Im Htp fut adoré dans cette région. Le nom de Memphis est mentionné à plusieurs endroits dans la Bible. "Ils sont devenus stupides, les chefs de Tanis, les chefs de Memphis sont dans l'illusion, Ils font vaciller l'Égypte, eux, la Pierre angulaire de ses tribus". "Fais tes baluchons pour l'exil population de l'Égypte; Memphis deviendra une étendue désolée, brûlée, inhabité". "Même les gens de Memphis et de Daphné te défoncent le crâne"; "Ainsi parle le Seigneur Dieu: Je ferai périr les idôles, je supprimerai de Memphis les faux dieux et du pays d'Égypte le prince; Il n'y en aura plus. Je metterai la crainte dans le pays d'Égypte. Je mettrai le feu à l'Égypte, Sîn, se tordra de douleur. Thèbes sera fendue, Memphis sera inondée". "Même les gens de Memphis et de Daphné te défoncent le crâne. Faîtes-le savoir en Égypte. Faîtes le entendre à Memphis et de Daphné, dîtes: Dresse-toi! En garde! L'épée dévore autour de toi”. Es. 19:13; Ez. 30: 13-16; Jr. 2:16; 46:14; 'ABD ALHALIM NUR AL-DIN, al-Luga al-mișrȳya al-qadīma, $\mathrm{V}^{\text {th }}$ ed., Le Caire, 2003, p. 329.

(5) C'est le plus ancien manuscrit qui mentionne la biographie de la martyre Mohraté. Manuscrit Paris-arabe $n^{\circ}$ 73, f. 1; Y. T. AL-HuMI, Sìrat, p. 104.

(6) N. SALĪM, Abtāl, p. 29. 


\section{MOHRATÉ UNE SAINTE COPTE OUBLIÉE PAR L'HISTOIRE}

l'ouest de Ḥilwān sur la rive ouest du Nil ${ }^{(1)}$ tout près de Saqqara ${ }^{(2)}$ où se trouve, actuellement, le monastère copte de saint Mercure $^{(3)}$ connu sous le nom du monastère de Tamwīh ${ }^{(4)}$. L'historien ABU'L-MAKARIM affirme, à son tour, l'opinion d'AL-ŠABUSTI (fig. 4). Il ajoute, également, qu'il y avait, là, l'église des saints Côme et Damien, leurs frères et leur mère ${ }^{(5)}$. Le même historien a mentionné que cette église a a été restaurée par al-Šaih $\mathrm{Abū} \mathrm{Sa} a^{\text {‘̄d }}$ al-Kātib ${ }^{(6)}$. ABU ȘALIḤ, à son tour, tour, affirme qu'à Țamwīh, une église a été édifiée en l'honneur de Maharaté ${ }^{(7)}$. L'historien mamlūk AL-MAQRIZI nous parle, lui-aussi, du monastère de Țamwīh, actuellement, entouré des arbres, des palmiers et des vergers. ${ }^{(8)}$ YAQUT AL-HAMAWI signale, également, ce monastère monastère ${ }^{(9)}$. Selon 'Ali MUBARAK ${ }^{(10)}$ et MuHAMMAD RAMzI, ${ }^{(11)}$ ce

(1) AL-ŠĀBUŠTī, Kitāb al-dīyārāt, publié par 'AZĪZ SŪRİYĀL 'A ȚTYYA, Le Caire, 1939 et plus tard publié par KURKIS ‘AWĀD, Bag̉dād 1951, pp. 194-195; ABŪ ȘĀLIḤ (THE ARMENIAN), Churches, p. 197, n 3; AL-MAQRĪZĪ, Kitāb al-mawā 'iz wa'l-i 'tibār bidikr al-hițtatwa'l-atâar, éd. de Būlāq, Le Caire, II, 1853, p. 504; Tārīh al-aqbāt al-ma 'rūf bi'l-qawl al-ibrīzì li'l- 'allāma AL-MAQRĪZİ, commenté par 'ABD ALMAĞĪD DĪYYĀB, Le Caire, 1998, pp. 160-161.

(2) G. ViAUD, Les pèlerinages coptes en Égypte, d'après les notes du Qommos J. MUYSER, Le Caire, 1979, p. 11, nº 11.

(3) À propos du monastère de Țamwīh, cf. L. LEROY, "Les couvents chrétiens", ROC, I, Paris (1908), p. 43; G. VIAUd, Pèlerinages, p. 11, no 11; Art. "Tārīh̆", alYaqaza, IV, p. 33; O. F. A. MeInARdus, Christians in Egypt: Orthodox, Catholic and Protestant Communities. Past and Present, Cairo, 2006, pp. 197-198.

(4) M. RAMZī, al-Qāmūs, II, p. 588.

(5) R. BASSET, "Synaxaire arabe jacobite (rédaction copte), 2. Les mois de hatour et de kihak; 5. Les mois de Baounah, abib, mesoré et jours complémentaires", PatrOr., XVII/3, Tunhout/Belgique (1906,1923), pp. 330, 588.

(6) ABU’L-MAKARIM, Tārīh̆, II, pp. 121-123.

(7) ABŪ ȘĀLIḤ (THE ARMENIAN), Churches, f. 67 (b), pp. 197- 198, note n4.

(8) AL-MAQRīZĪ, Hitaț, II, p. 504.

(9) Jacut's geographisches Wörterbuch. Herausgegeben von Ferdinand Wüstenfeld, II, Leipzig, 1867, p. 674.

(10) 'Alī MuBĀRAK, al-Hițtat al-tawfíqūya al-ğadída limi șr al-Qāhira wa mudunihā wabilādihā al-qadīma wa'l-šahīra, XI, Le Caire, s. d., p. 35.

(11) M. RAMZī, Qāmūs, II/3, pp. 20-22. 
village connu, aussi, sous le nom de Dammūh se trouve dans le gouvernorat de Guizèh. Le nom de Dammūh est, déjà, mentionné dans l'ouvrage d'IBN MAMMATI ${ }^{(1)}$. Dans son article publié en 1939, 'AZIZ SURIYAL 'AṬIYA a affirmé les paroles d'AL-ŠABUSTI en ajoutant que le monastère est entouré de vergers, d'arbres et de palmiers mais il l'a mentionné sous le vocable arabe "دير طميه" (2).

Dans une autre feuille du même manuscrit de la bibliothèque nationale de la France, nous lisons encore le nom de Țamwīh:

$$
\text { "فى الساحل من طمويـه...". }
$$

C'est à dire, "sur le côte de Ṭamwīh". Sur le verso de la feuille ${ }^{\circ} 33$ du même manuscrit, nous lisons aussi les détails suivants:

$$
\text { "كانت معها فى بلدها التى هى من طمويه صبيـة تسكن بجوارها تزوجت من أهل }
$$

C'est à dire: "Il y avait avec elle dans son village appelé Ṭamwīh une fille habitée à côté d'elle et qui s'est mariée d'un des citoyens de la ville de Memphis. Sa mère était une veuve qui habitait à Țamwīh". Sur le recto de la feuille $\mathrm{n}^{\circ} 35$ du même manuscrit, nous lisons:

$$
\text { "أن صبياً فى ضيعة تسمى طُرا شرقى طدّوه ... جرجس ابن عم القديسة مهرائى ..". }
$$

C'est à dire: "Un garçon dans un banlieu appelé TTura à l'est de Ṭammūh ... George le cousin de la sainte Muhrā'ì ...".

É. AMELINEAU a mentionné que Țammā à Sohāğ est le village où était originaire la sainte Mohraté. Signalons que Țamwīh et Dammūh sont les noms d'une autre région que celle de Țammā ou bien Țimā qui se trouve en Haute-Égypte et qui est un des anciens villages et districts. H. GAUTHIER a, lui-aussi, mentionné le nom de Țammā ou bien Țimā qui est fondé en 1844 dans son dictionnaire des noms géographiques sous le nom de $\operatorname{Tantm}(t)$. Il a, également, ajouté que ce nom qui signifie

(1) IBN Mammati, Qawānīn al-dawāwīn, réalisé par 'Azīz Surīyāl 'Ațyya, Le Caire, 1943, p. 134.

(2) 'AZĪZ SURĪYĀL 'AȚīYA, "Some Egyptian Monasteries According to the Unpublished MS. of al-Shābusht̄̄'s. Kitāb al-Diyārāt", BSAC, V, Le Caire (1939), pp. 6, 20-21. 
la perfection est celui d'une ville du $\mathrm{X}^{\mathrm{e}}$ nome de la Haute-Égypte (Aphroditopolis) $^{(1)}$. Il semble qu'É. AMELINEAU a confondu entre Țamwīh qui se trouve tout près de Memphis et entre Țimā qui est tout près de Kūmm Išqā ${ }^{(2)}$. Ce village connu aussi sous les noms de Ṭammā, Țamā, Țamyeh ${ }^{(3)}$ et Ṭamāw ${ }^{(4)}$, est également mentionné sous le


NTME $\epsilon \omega d Y$ MOYTE EPOY $x \in$ TdMd $"$ "(5).

D'après G. SALMON, Timā est à l'est du gouvernorat de Fayyūm vers le sud ${ }^{(6)}$. Dans le synaxaire arabe jacobite, le nom de ce village est Țamā: "Ṭamā dans les nahiets de Qāou"(7). Au VI $\mathrm{V}^{\mathrm{e}}$ siècle, ce village appartenait à l'évêchée d'Ahmīm mais il est devenu, plus tard, sous la domination d'Abū Tīğğg. Aujourd'hui, Țamā est dans les nahiets de Qāou sur la rive ouest du Nil "Qāou al-sug̀nā",(8). Ce nom affirme qu'il y y avait un autre district appelé "Qāou al-kubrā",(9) qui était une évêchée

(1) Sous le règne des Romains, cet ancien village connu sous le nom de Poukhis avait un port appelé port d'Antéopolite qui se trouvait entre Asīyūṭ et Ahmīm. IBN MAMmATI l'a mentionné sous le nom de Țimā al-Ṭin. H. GAUTHIER, Dictionnaire des noms géographiques contenus dans les textes hiéroglyphiques, V, Le Caire, 1929, pp. 23-24; M. RAMZI, Qāmūs, II/4, pp. 138-136.

(2) Ancienne ville connue sous le nom religieux de per zbaoui. Son nom copte est KooY ou bien tw2dY. Plus tard, ce village a reçu le nom arabe إثشـقوة. É. AmelineaU, Géographie, pp. 477-478; M. Ramzī, Qāmūs, II/4, p. 136; N. SALIM, $A b t a \bar{l}$, pp. 30-32.

(3) G. SALMON, "Répertoire géographique de la province du Fayyūm d'après le kitāb tārīh al-Fayyūm d'AL-NABULSI", BIFAO, I, Le Caire (1901), pp. 36-37.

(4) al-Qidīsa, p. 7.

(5) É. AMELINEAU, Géographie, p. 474.

(6) G. SALMON, Répertoire, pp. 36-37.

(7) "فى طما من نواحى مدينة قاو (7) Le nom de Qaw ou bien Qāou nous rappelle de la région archéologique connue sous le nom de Kūmm Išqāa كوم إثقاو (Aphroditopolis) tout près de Mišțā. É. AmÉLINEAU, Géographie, p. 475; 'A. NŪR AL-DĪN, Lugia, p. 328 .

(8) É. AmelineaU, Géographie, p. 474; al-Qidīsa, p. 19.

(9) J. HORN a mentionné le nom de Qāw (al-kabīr) ou bien TKOW/TKOoY dans son ouvrage publié en 1986. Cf. J. HoRN, Studien zu den Märtyrern des Nördlichen 
independante ${ }^{(1)}$. Toutes les notices du synaxaire arabe jacobite sont en relation avec un seul et même village qui se trouvait sur la rive gauche du Nil non loin de Qāou ${ }^{(2)}$. D'après É. AmELINEAU, il s'agit de quatre mentions de Tamā dans le synaxaire. La première est visible en parlant de la fête de la sainte: "On enterra son corps à Tamā son pays car son père était prêtre $d u$ village et on bâtit sous son invocation une magnifique église بيعة عظيمة. Le nom, cependant, mentionné dans le synaxaire est Ṭammâou et non pas Ṭamā.

D'après É. AMELINEAU, Maharaté fut enterrée à Sohāğ et non plus à Tammôou le village qui se trouve dans le district de Badrašīn au gouvernorat de Guizèh $^{(4)}$. Si l'opinion de É. AMELINEAU est correcte, l'église, actuellement, édifiée là-bas lui donc appartient (pl. II). Ainsi elle serait la première martyre enterrée dans ce village qui se trouve dans le gouvernorat de Sohāğ en Haute-Égypte. Signalons, en outre, que le village de Țimā qui se trouve, actuellement, à Sohāğ n'était pas connu par ce nom avant le $\mathrm{XII}^{\mathrm{e}}$ siècle, c'est à dire, 800 ans après la mort de sainte Mohraté. À l'époque romaine et du vivant même de cette sainte, ce village, connu sous le nom romain de Poukhis, avait aussi un port appelé Antéopolite qui existait entre la ville d'Ahmīm ${ }^{(5)}$ et celle d'Asīyūt ${ }^{(6)}$ comme c'est déjà mentionné. Ce village se trouve à l'Est de Fayyūm vers le Sud. Banū Zar'a étaient les habitants de cette région

Oberägypten, I. Märtyrerverehrung und Märtyrlegende im werke des Shenute, Beiträge zur Ältesten Ägyptischen Märtyrerüberliefer-ung, Coll. Göttinger Orientforschungen 4. Reihe: Ägypten, Band 15, Wiesbaden, 1986, pp. 64-66, 130.

(1) al-Qidīsa, p. 19.

(2) É. AMÉLINEAU, Géographie, p. 475.

(3) R. BASSET, "Synaxaire”, PatrOr., XI/5, pp. 594-598, 14 ṭ̄ba/19 janvier; É. AMELINEAU, Géographie, p. 474.

(4) É. AmelineaU, Géographie, pp. 477-478; al-Qidīsa, p. 13.

(5) Les deux dieux Horus et Min étaient adorés dans cette ville connue sous le nom égyptien de hnt mn et sous le nom grec de Panopolis. 'A. NŪR AL-Dīn, Lugia, pp. 283, 328.

(6) M. RAMZī, Qāmī̄s, II/4, pp. 135-136; Y. T. AL-ḤūMī, Sìrat, p. 105. 
arrosée par l'eau du Nil, contrairement, aux terres du Fayyūm arrosés par des sāqīya (norias) $)^{(1)}$.

É. Amelineau a, aussi, mentionné que le corps de sainte Mohraté est enterré à $10 \mathrm{~ms}$ sous son église, actuellement, édifiée dans le monastère de la sainte Damienne tout près de celui d'Abū Fāmm alĞundì à Tamā ${ }^{(2)}$. La seconde mention est citée dans l'abrégé des actes du martyr Begoush dont la phrase est ridigé par le vali Arien comme suit: "et les soldats le conduisirent dans le village de Tama, du pays de Qāọt, un peu à l'ouest". La troisième mention se rapporte au même endroit comme suit: "On bâtit en son nom une église à l'Ouest de Tama, près d'un village appelé al-Sehnoun"(3). É. AMELINEAU cite les noms d'autres martyrs coptes de Ṭamā comme saint Paési ${ }^{(4)}$ (пגHc€)

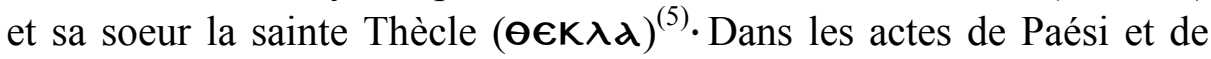
Thècle, la Vierge conduisit une jeune fille tout près de son frère qui

(1) G. SALMON, Répertoire, p. 37.

(2) al-Qidīsa, p. 9.

(3) R. BASSET, “Synaxaire”, PatrOr., XI/5, 26 țāba/21 janvier; É. AmelineaU, Géographie, p. 474.

(4) Un personnage connu sous ce nom est invoqué dans les litanies coptes sans toutefois avoir le qualificatif $2 \mathrm{~A} \Gamma \mathrm{IOC}$. Rien n'aide à identifier ce saint invoqué à Wādī Sarğa. Nous connaissons un autre martyr appelé Paési parmi les martyrs égyptiens de la Palestine et nous le retrouvons dans le synaxaire de

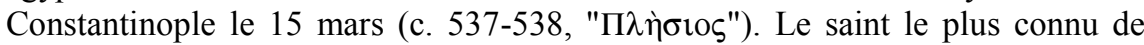
l'hagiographie copte est, cependant, Paési qui fut martyrisé avec sa soeur Thècle du duc de la Thébaide Eutychianus. Originaires tous les deux de Pousire près d'Hermopolis, ils sont commémorés dans le synaxaire arabe jacobite le $8 \mathrm{kiohk} / 4$ décembre. Leur martyre eut lieu dans un endroit appelé Tepot/T€ாஸт. Ce toponyme est attesté dans l'Hermopolite ainsi qu'au nord de Šatanūf dans le Delta. Cf. T. BAUMEISTER, Martyr Invictus. Der Martyrer als Sinnbild der Erlösung in der Legende und im Kult der fruhen koptischen Kirche. Zur Kontinuität des ägyptischen Denkens, Münster, 1972, pp. 123-124; E. A. E. REYMOND and J. W. B. BARns, Four Martyrdoms from the Pierpont Morgan Coptic Codices, Oxford, 1973, pp. 31-79; M. BRownE, "the Martyrdom of Paese and Thecla (P. Mich. Inv. 548)", ChronEg., IXL, Bruxelles (1974), pp. 201-205; T. ORLANDI, "Paese and Tecla, saints", CoptEnc., VI, p. 1865; A. PAPACONSTANTINOU, Le culte des saints en Égypte des Byzantins aux Abbassides. L'apport des inscriptions et des papyrus grecs et coptes, Paris, 2001, p. 163.

(5) É. AmelineaU, Géographie, p. 474; al-Qidīsa, p. 19. 
était malade. Nous y lisons: "Elles arrivèrent en face d'un petit village qu'on nomme Tammah"(1). Dans un autre récit, un solitaire dit: "Paul, c'est mon nom, et je suis un homme de Tammā, dans le nome de Koeis"(2). L'analyse des actes de Bifām comporte, par ailleur, la quatrième mention. Le gouverneur ayant voulu se rendre d'Antinoë à Ahmīm, sa barque s'arrêta. On lui a appelé un magicien qui n'y a pu rien. Il a voulu manger et son bras se paralysa. Il a enfin dit cette phrase: "et les soldats marchèrent avec lui (le martyr) vers un village nommé Tamà à l'ouest du village, sur une colline élevée"(3).

\section{2. Église de sainte Mohraté:}

Dans l'Histoire des patriarches, nous lisons qu'En Égypte, nous trouvons, actuellement, le corps de Abba Ḥor et de sa soeur Muhrā'îl ou bien Muhrāȳill ${ }^{(4)}$, et on nous parle d'une église qui existait, aussi, sous le ponctificat du patriarche copte $\mathrm{n}^{\circ} 68$ Michel (1092-1102) au sud-est du Vieux Caire tout près de Birkat al-Habaš ${ }^{(5)}$ et de la digue de Banī $\mathrm{Wā}^{\prime} \mathrm{il}^{(6)}$. Cette église dédiée à Abū Qūdāma contenait trois chapelles avec trois autels: Le premier était consacré à saint Pachôme, le second était celui de sainte Muhrā'îl la vierge martyre et le dernier était dédié à saint Sawiros le patriarche copte ${ }^{(7)}$. AL-MAQRIZI ne mentionne pas cette cette église dans ses ouvrages ridigés au $\mathrm{IX}^{\mathrm{e}} / \mathrm{XV}^{\mathrm{e}}$ siècle probablement parce qu'elle a été détruite avant son époque.

(1) É. AMELINEAU, Géographie, p. 474.

(2) G. D. Zö̈GA, Catalogus Codicum Copticorum Manu Scriptorum qui in Museo Borgiano Velitris Adservantur, Roma, 1810, p. 360; É. AMELINEAU, Géographie, p. 474.

(3) É. AMÉLINEAU, Géographie, p. 475.

(4) History of the Patriarchs of the Egyptian Church Known as the History of the Holy Church, II/3. Christodoulos-Michael (1046-1102 A. D.), traduit et annoté par 'AZIZ Suriyal 'AȚiYA, YASSA 'ABD AL-MASIH et O. H. E. KhS. BURMESTER, Le Caire, 1959, p. 227, note $\mathrm{n}^{\circ} 8$.

(5) Ce n'était pas une rivière mais plustôt des terrains agricoles arrosés par l'eau du Nil lors de la crue annuelle. M. G. DARESSY, Indicateur, p. 190; M. RAMZĪ, Qāmūs, I, pp. 150-151; Y. T. al-Ḥūmī, Sìrat, p. 99.

(6) M. RAMZī, Qāmūs, I, pp. 150-151.

(7) History of the Patriarchs, II/3, pp. 227, 397. 
Une autre église, qui a été dédiée à Mohraté à Manīyal Šịha au Guizèh tout près du monastère des saints Côme et Damien ${ }^{(1)}$, fut édifiée le 22 misrā/ 15 août 314 , deux ans à peu près, après l'édit de Milan (312). En effet, quatre archons de Memphis: Athanase, George, Marc et Théodore, se sont présentés au patriarche copte pour lui avouer leur désir de bâtir une église à sainte Mohraté et ils l'ont édifiée dans presque deux ans ${ }^{(2)}$. Le manuscrit de la Bibliothèque National de la France affirme cette histoire. Au verso de la feuille $n^{\circ} 36$ de ce manuscrit, nous lisons:

$$
\begin{aligned}
& \text { "عند ذلك بُنيت الكنايس (sic) على اسم القديسة العذرى (sic) مُروائى وبيت ابويها } \\
& \text { بطمويه بناها جماعة من اهل منف وأهل طمويه....". }
\end{aligned}
$$

En voici la traduction: "Là-bas, des églises furent édifiées (sic) au nom de la sainte la vierge (sic) Muhrā'̄ et la maison de ses parents à TTamwīh a été construite par un groupe des citoyens de Memphis et de Tamwīh". Le manuscrit, qui comporte la biographie du saint martyr Apater "Abādīir" et de sa soeur Heraïs/Eirène "Irān̄̄" et qui est, actuellement, conservé dans le monastère des Syriens à Ouadi Națroun,

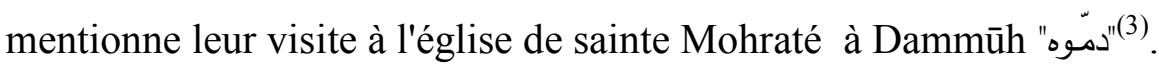

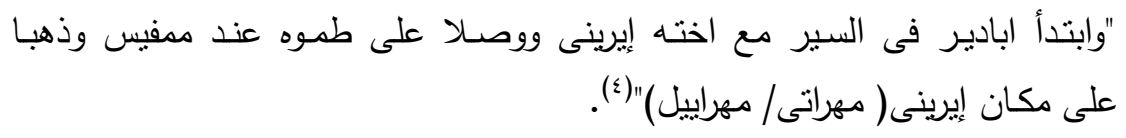

En voici la traduction: "Apater commença à marcher avec sa soeur Eirène et ils arrivèrent à Țamūh tout près de Memphis. Ils sont allés à la place de Eirène (Mohraté/Muhrā'̄1). Dans son ouvrage publié en 1886, H. HyVERnAT a signalé que cette histoire eut lieu sous le règne de l'empereur romain Dioclétien (284-305) qui a fabriqué et qui a adoré les idôles. H. Hyvernat a, également, ajouté que: "beN

(1) Pour plus d'informations à propos de ces saints, cf. A. J. FeSTUGIERE, Sainte Thècle. Saints Côme et Damien, Saints Cyr et Jean (extraits). Saint Georges, coll. grecques de miracles, Paris, 1971.

(2) Art. “al-qiddīsa Muhrā’îl”, Madāris al-ahād, VII, Le Caire (15 août 1997), pp. 1011; Y. T. al-HumI, Sirat, p. 96.

(3) Manuscrit de la biographie d'Abādīr, f. 33; Y. T. AL-HuMI, Sïrat, p. 105.

(4) Manuscrit de la biographie d'Abādīir, f. 33. 




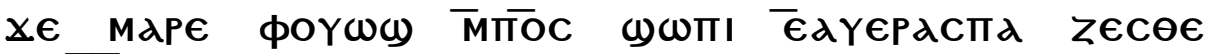
NNOYEPHOY AYZITOTY АЧMOWI NEM TEYKOYXI N CWNI OYO2 OYI ETAMMWOY NTE MEM4I AY€ NWOY EாTOTOC

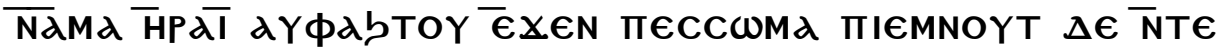

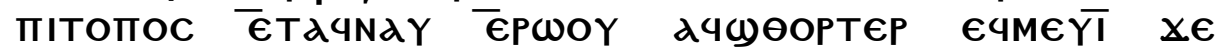

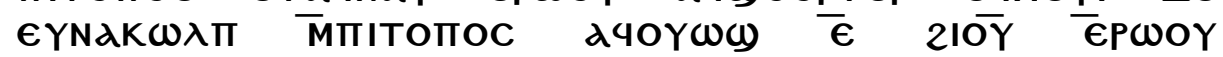

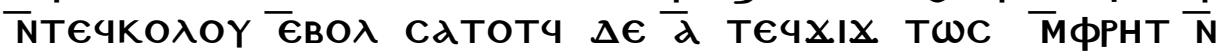



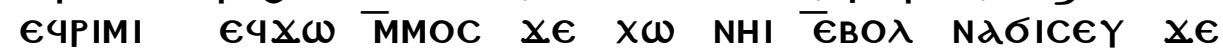
AIEPNOBI EPWTEN bEN OYMETATEMI d4T $\Delta \epsilon$ XE

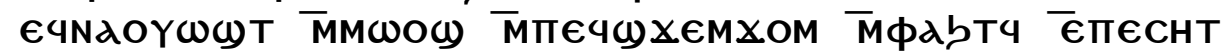



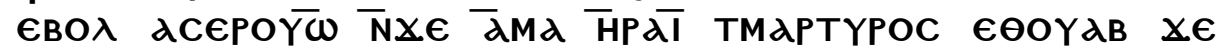

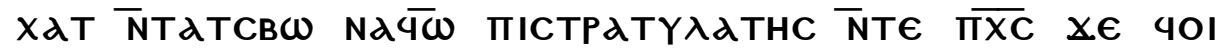

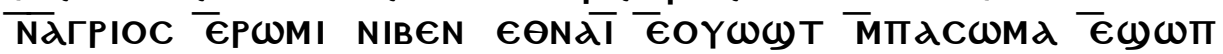



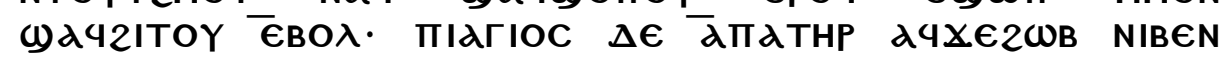

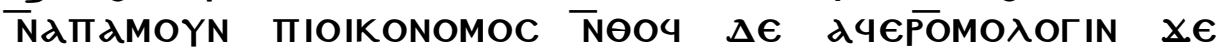

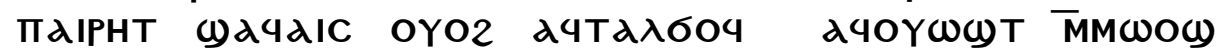
€4XW MMOC XE NAOICEY NOWTEM NAdW MMd TEXWOY



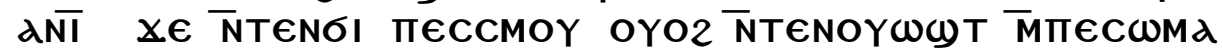



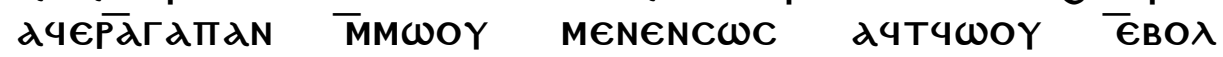

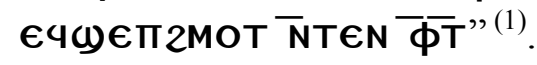

En voice la traduction de H. HYVERNAT: "Quand saint Apater eut entendu ces paroles, il dit: Que la volonté du Seigneur soit faite. Les deux saints s'embrassèrent l'un l'autre (et Apater) commença à marcher, avec sa jeune soeur. Ils arrivèrent à Tammoôu de Memphis, se rendirent au topos d'Ama Irai et se prosternèrent sur son corps. En les voyants, le portier du topos se troubla croyant qu'ils venaient piller le topos et voulut les frapper pour les chasser. Aussitôt sa main devint raide comme une pierre. Il ne sut que faire et cria, pleurant et disant: Pardonnez-moi, mes seigneurs, $j$ 'ai pêché contre vous, par ignorance et il vint pour les adorer, mais il ne put pas se prosterner. Alors saint Apater pria Ama Iraï, disant: Pardonne-lui. Ama Iraï, la sainte

(1) H. HYVERNAT, Les actes des martyrs de l'Égypte tirés des manuscrits coptes de la bibliothèque Vaticane et du Musée Borgia. Texte copte et traduction française avec introduction et commentaires par H. HYVERNAT, I, Paris, 1886, pp. 94-95. 
martyre, répondit: Laisse-moi lui donner une leçon, ô capitaine du Christ. Il est féroce envers tous ceux qui viennent vénérer mon corps. Si on lui fait un don, il reçoit les gens; si non, il les chasse. Saint Apater raconta tout cela à Ap'Amoun, l'économe. Celui-ci leur avoua que le portier faisait vriament ainsi. Puis Apater le guérit. Et le portier adora (les deux voyageurs), disant: Mes seigneurs, d'où êtes-vous? Ils répondirent: Nous sommes étrangers. Nous avons entendu (parler) d'Ama Iraï, et nous sommes venus recevoir sa bénédiction et adorer son corps. Ap'Amoun l'économe les mena chez lui (et les garda) deux jours; il les prit en affection. Puis, il les reconduisit en rendant grâce à Dieu" ${ }^{(1)}$. T. BAUMEISTER a affirmé, lui-aussi, la visite de saint Apater et sa soeur Herais à sainte Mohraté à Tammow de Memphis ${ }^{(2)}$. H. DELEHAYE, à son tour, a mentionné que saint Apater et sa soeur Herais, qui furent martyrisés le 28 tūt $/ 25$ septembre $^{(3)}$ par Arianus le gouverneur d'Antinoë ${ }^{(4)}$, se sont rendus à la visite de saint Mohraté. Dans l'ouvrage publié, en 1974, par T. ORLANDI, nous lisons les noms coptes des deux saints Apater et sa soeur Erai comme suit: [T€M


le même ouvrage, nous pouvons lire: "Unico é il Dio dell' apa Ter e di

(1) I Papyri Copti, I/5, p. 5; H. Hyvernat, Actes, I, pp. 78, 94.

(2) T. BAUMEISTER, Martyr, p. 102.

(3) Le synaxaire arabe jacobite nous apprend que saint Apater et sa soeur Iraei furent martyrisés le 28 tūt et qu'Apater fut le fils de la soeur de Basilidis le vizir d'Antioche. En plus, Apater a exercé les fonctions du général à la place de son père. R. BASSET, "Le synaxaire arabe jacobite (rédaction copte)", 1. Les mois de Tout et de Babeh, Texte arabe publié, traduit et annoté par R. BASSET, PatrOr., I, Turnhout/Belgique (1910), p. 303; DE LACY O'LeARY, Saints, pp. 79-80.

(4) Ce même auteur signale que des églises furent édifiées à un saint Apatir ou Abadir le 16 Epip. Il ajoute, également, qu'ABU ȘALIḤ a précisé ces églises à Mallawī et à al-Bahnasa. Il semble, aussi, qu'un autre saint Apater est mentionné sous le nom d'Abaddir ou Abbadiri sancto Manlianae. Cf. H. DelehaYe, Les martyrs d'Égypte, Bruxelles, 1924, pp. 94, 109; H. DELEHAYE, Sanctvs. Essai sur le culte des saints dans l'antiquité, Bruxelles, 1927, p. 12. 


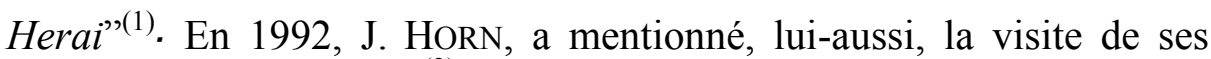
deux saints à Ama Herai ${ }^{(2)}$.

Les historiens affirment qu'à Dammūh (دمّهوه), il y avait, également, le monastère de saint Mercure en plus de cinq églises consacrées à saint George, sainte Mohraté, Abba Bimā, l'archange Michel et la sainte Vierge Marie $^{(3)}$ (figs. 2/a-b). Après la destruction de l'église de sainte Mohraté, ses ruines ont été renfermées dans le monastère actuel des deux saints Côme et Damien et qui fut édifié au $I V^{\mathrm{e}}-\mathrm{V}^{\mathrm{e}}$ siècle. Ce dernier monastère a été, plus tard, restauré au XII ${ }^{\mathrm{e}}$ siècle comme l'a mentionnée Irīs al-Mișrī dans son ouvrage intitulé: "Qișat al-kanīsa almişrȳya" et publié, au Caire, entre les années 1961-1990. L'église du monastère, également, restaurée au $\mathrm{XIX}^{\mathrm{e}}$ siècle, a été, récemment, renouvelée au $\mathrm{XX}^{\mathrm{e}}$ siècle à la suite du séïsme qui a eu lieu en 1992. La région, où fut édifiée cette église, était connue, auparavant, sous le nom

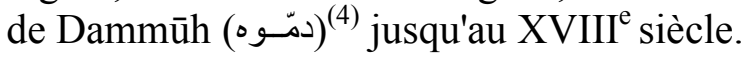

Dû à la destruction de l'église originelle de Mohraté, aux $\mathrm{XI}^{\mathrm{e}}$ et $\mathrm{XIV}^{\mathrm{e}}$ siècle, il n'y a aucune icône archéologique qui la représente et ce fut, probablement, la raison pour laquelle les gens l'ont oubliée. Signalons, aussi, que la biographie de sainte Mohraté a été publiée pour la première fois en 1984 puis en $1995^{(5)}$. Dès cette date, la fête de la consécration de son église tient lieu, annuellement, le 22 misrā/28-29 août ${ }^{(6)}$.

\section{Description du monastère des saints Côme et de Damien à Mañ̄yal Šịha}

(1) T. ORLANDI, Koptische Papyri theologischen Inhalts. Hrsg. und in das italianisches Übersetzt. (MPÖN S. 9), Wien (1974), pp. 149-154 ("Martirio di Ter ed Erai"), p. 152.

(2) Dans l'ouvrage de J. HoRN, saint Apater est, également, mentionné sous le vocable de Aba Dér ou bien Abba Dér. Nous lisons, aussi, le nom de sa soeur Erazi. J. HORN, Studien, II, pp. 87-94.

(3) ABū'L-MAKĀRIM, Tārīh II, p. 123; O. F. A. MeInardus, Christian Egypt. Faith and Life, Cairo, 1970, pp. 168-169; Y. T. AL-Ḥ̂̄MĪ, Sìrat, p. 18.


III, pp. 19-22.

(5) Y. T. AL-HŪMĪ, Mu' 'ğizāt, p. 15; N. ZuQLuma, Muhrā'īl, pp. 5, 10.

(6) Y. T. AL-HŪMĪ, Mu' '̆izāt, p. 16. 
Après avoir parlé de l'église de Mohraté, nous traiterons en détails la biographie et le couvent de Côme et de Damien à Manīyal Šīha et qui remonte au $\mathrm{IV}^{\mathrm{e}}-\mathrm{V}^{\mathrm{e}}$ siècle $\left(\mathbf{p l}\right.$. I) ${ }^{(1)}$. Tout d'abord, Côme et Damien qui étaient, en effet, deux saints médecins populaires et qui étaient spécialisés dans les guérisons des tremblements nerveux et d'épilepsie, c'est pourquoi, ils sont très connus dans le monde entier ${ }^{(2)}$. Ils soignaient les malades notamment les pauvres et les malheureux sans prendre ni argent ni cadeaux ${ }^{(3)}$. D'après G. VIAUD, ils paraissent être d'origine syrienne ${ }^{(4)}$. Leur famille fut originaire d'une ville dite Eagea "ارابيـا" ou encore Dabarmâ à Arâbyâ" ${ }^{(5)}$. En effet, c'est un port au nord de l'Arabie Saoudite. Côme et Damien avaient trois autres frères ermites: Antimos/ Anthime, Lawindios/Léonce et Ibrabios/Euprépius. Les cinq frères étaient les fils d'une femme appelée Théodora/Tâoudoudâ qui était compatissante et qui craignait le Seigneur. Les trois frères se sont retirés dans le désert pour embrasser la vie monastique ${ }^{(6)}$. À cette époque, l'empereur Dioclétien qui adorait les idôles, a ordonné à tous ses sujets de les adorer. Apprenant que Côme et Damien prêchaient la Messie dans la ville et qu'ils anéantissaient les idôles, il a ordonné de les arrêter et il les a livrés à Asius le gouverneur de la ville qui les a torturés. Ayant refusé de dénier leur foie devant l'empereur romain, les cinq frères ainsi que leur mère

(1) Nous arrivons, actuellement, à l'église des saints sages et moines coptes Côme et Damien par métro (ligne 2) et nous descendons à la derrière station dite "alMunīb". Le visiteur peut prendre après une voiture jusqu'à la station d'essence dite "Total". Il peut prendre, aussi, l'autobus de la place Ramsés. Il peut se servir, également, de l'autobus qui part de l'Université du Caire. Le visiteur prendra ensuite la rue à gauche jusqu'à ce qu'il arrive à un canal transversal qui s'étend, parallélement, aux chemins de fer. Après avoir traversé les chemins de fer et le canal, il continuera à droite pour entrer, à gauche, dans la deuxième rue étroite et il doit continuer jusqu'à la fin où se trouve le bâtiment actuel du monastère.

(2) G. Viaud, Pèlerinages, p. 41.

(3) R. BASSET, "Synaxaire", PatrOr., III, p. 330.

(4) G. Viaud, "Pilgrimages”, CoptEnc., IV, p. 1973.

(5) G. Viaud, Pèlerinages, p. 41.

(6) R. BASSET, “Synaxaire”, PatrOr., III, p. 330. 
ont été torturés et martyrisés ${ }^{(1)}$. Quiconque se rendra, aujourd'hui, à la visite de l'église principale de la Vierge Marie dans le monastère des Syriens à Wādī Națūn verra les figures des saints Côme et Damien sur la paroi sud du choeur.

Le général courageux Victor fils de Romanos ${ }^{(2)}$ a eu le courage d'enterrer le corps de leur mère sans se soucier des ordres impériales, c'est pourquoi il a été exilé à Asīyūt en Haute-Égypte où il est mort le 27 barmūda/22 avril ${ }^{(3)}$. Une église lui a été édifiée dans l'endroit connu sous le nom de Dair al-Ğabrāwī ${ }^{(4)}$ à Abnūb. Plus tard, une partie des reliques des saints Côme, Damien, leurs frères ermites et leur mère fut transportée en Égypte, notamment, au Guizèh où se trouve, actuellement, leur monastère à Manīyal Šị ḥa. Ainsi, la fête de leur martyre est célébrée, annuellement, le 22 hātūr/18 décembre ${ }^{(5)}$ comme c'est déjà mentionné dans le synaxaire. Ils sont, aussi, célébrés à deux autres dates différentes selon le calendrier de l'Église Copte Orthodoxe: le 22 bā'ūna/ 16 juin $^{(6)}$ et le 30 hātūr/ 9 décembre le jour de la dédicace de leur église et l'apparition de leurs miracles, c'est pourquoi, plusieurs malades se rendent, annuellement, à ce monastère pour chasser les mauvais esprits et pour se guérir comme ils le croient. L'Église Latine fête leur mémoire en les citant au Canon de l'Anaphore Romaine et aussi aux litanies des saints. Ainsi une ancienne église leur fut dédiée à

(1) R. BASSET, "Synaxaire", PatrOr., III, p. 332; G. VIAUd, "Pilgrimages", CoptEnc.,

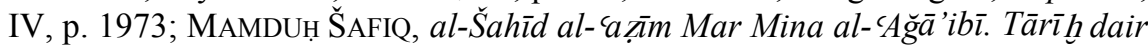
Mar Mina bifumm al-Halĭg, I ìre éd., Le Caire, 2003, p. 259.

(2) Il était le fils de Marthe qui fut chrétienne et de Romanos qui fut le conseiller de l'empereur Dioclétien. Victor était toujours contre le culte des idôles. R. BASSET, "Synaxaire", PatrOr., III, p. 332; XVI, pp. 185-424; É. AMELINEAU, Actes, p. 165.

(3) R. BASSET, “Synaxaire”, PatrOr., XVI, pp. 338-339, 27 baramouda/22 avril.

(4) Ce cimetière, qui se trouve sur la rive est du Nil en face de Manfalūṭ, comprend à peu près cent tombes des nomarques de Thèbes. Ces tombes remontent à la $\mathrm{XXVI}^{\mathrm{e}}$ dynastie. 'ABD AL-ḤALIM NUR AL-DIN, Mawāqi' wa matāhif al-atāar almişrìya, Le Caire, 1998, pp. 156-157.

(5) R. BASSET, “Synaxaire", PatrOr., III, p. 330, 22 hātūr/18 décembre.

(6) R. BASSET, "Synaxaire", PatrOr., XVII/3, p. 588, 22 baounah/16 juin; 'ABD ALMASIH ȘALIB AL-MAS'UDI AL-BARAMUSI, Tuhfat al-sā'ilīn fì dikr adyurat ruhbān al-misrīyìn, Wādī al-Națrūn, 1998, pp. 137-138. 
Rome bâtit sous les ordres du Pape Félix (526-533) ${ }^{(1)}$ et plusieurs autres églises furent, également, construites à leurs noms en d'autres endroits en Égypte. Ils avaient une église à Bāb al-Ḥadīd (l'actuelle place de Ramsès), une deuxième église à Alexandrie et une troisième dans le monastère de anba Arsānīyus connu sous le nom de Dair al-Baġl à la montagne de Tura. Deux autres églises leur furent consacrées l'une à Aṭ̂ị et l'autre à Qūş en Haute-Égypte. On leur a édifié d'autres églises en Europe comme l'église de Bremen et la cathédrale d'Essen en Allemagne. Notons, aussi, l'église archéologique de Paris.

L'actuelle église du monastère des saints Côme et de Damien à Manīyal Šịha fut mentionnée au XII ${ }^{\mathrm{e}}$ siècle par l'historien ABU'LMAKARIM $^{(2)}$ (figs. 2/a-b) puis dans l'Histoire des patriarches comme c'est déjà mentionné. Les moines y vivaient jusqu'au $\mathrm{XIV}^{\mathrm{e}}$ siècle. D'après AL-MAQRIZI, ce monastère est, également, connu sous le nom de Dair Dumwat al-Sibā' "دمـوة السـباع". Le même historien et G. VIAUD l'ont mentionné encore sous le nom de Dair Lațīf $\mathrm{f}^{(3)}$ "ديـر لطيـف" AL-MAQRIZI a, également, ajouté que ce monastère qui fut auparavant habité par un sage appelé Saba "سـباع", a été vendu aux Juifs $^{(4)}$. M. G. DARESSY, qui a mentionné le monastère sous le nom arabe Dumwat al-Sibāh "دهـوه السـباخ" ou Dumwū' al-Sibā' , affirme cependant que tous les chroniqueurs arabes ont probablement confondu ce village qui se trouve dans le district de Dikirnis au gouvernorat de Daqahlīya avec la ville de Ṭamūh "طهـوه" qui se trouve au Guizèh ${ }^{(6)}$.

(1) G. VIAUd, Pèlerinages, p. 41.

(2) 'ABU'L-MAKARIM, Tārīh, II, p. 123.

(3) G. VIAUD, "Pilgrimages", CoptEnc., IV, p. 1973.

(4) AL-MAQRIZI, Hițt, II, p. 504; Tārīh, 160-161; L. LeROY, Couvents, p. 42; G. VIAUD, Pèlerinages, p. 41.

(5) Le temple de Moïse le prophète s'y trouvait sur la rive ouest du Nil. Le journaliste IBRĀHĪM ȘABRĪ affirme, aussi, que là se trouvait autrefois les ruines du palais $\mathrm{du}$ prophète Joseph à Memphis c'est pourquoi les Juifs visitaient, régulièrement, ce site. 'ABU'L-MAKARIM, Tārīhn, II, p. 123; AL-MAQRIZI, Tārīh, pp. 160-161; M. G. DARESSY, Indicateur, p. 206; M. RAMZI, Qāmūs, II/3, p. 20; IBRĀHĪM ȘABRĪ, "Dair Țammūh aqdam dair fî'l-cālam", Wațañ̄, n¹688, Le Caire (mai 1994), p. 9.

(6) M. G. DARESSY, Indicateur, p. 206. 
Un long serdāb reliait le monastère de Manīyal Šiḥa à celui de saint Mercure qui se trouve à Țamwīh sur l'autre rive du Nil. Il est probable que ce serdāb était utilisé durant les longues périodes de persécutions. Un grand portail flanqué de deux tours ornées de croix précède l'église (pl. I). Il s'agit, ensuite, d'un portail intérieur plus petit et qui est, à son tour, décoré d'une croix. L'entrée principale de cette église se trouve, actuellement, dans la paroi nord. De forme irrégulière, l'église comporte trois chapelles orientales. La chapelle centrale est consacrée aux deux saints sages coptes ${ }^{(1)}$ : Côme et Damien. Celle du sud est dédiée à la Vierge Marie et celle du nord est édifiée en l'honneur de sainte Maharaté/Mohraté. La partie centrale de l'église est couverte d'une gigantesque coupole supportée par quatre colonnes en marbre qui furent ramenées des anciens temples égyptiens et romains. Il semble que ces colonnes furent renversées durant la restauration, c'est pourquoi leurs bases se voient en haut et leurs chapiteaux sont enterrés sous le sol. À droite de l'entrée principale, la paroi nord est décorée d'icônes montrant les deux fameux saints coptes: Ménas et George. Sur la paroi ouest, il s'agit d'autres icônes qui représentent saint Victor, sainte Mohraté, saint Abanūb, un saint grec appelé Leimon (חаNT€ $\lambda € \mathrm{HMWN})$ et Abba Ishiroun al-Qillīnī ${ }^{(2)}$ dont la fête est célèbrée le 7 ba'ūna/14 juin ${ }^{(3)}$. Une des icônes qui apparaîssent sur cette paroi montre le Prophète Élie. Viennent après les icônes qui représentent saint Thècla Hemanot l'Éthipien avec Abba Nofer, sainte Hélène avec son fils l'empereur romain Constantin et enfin saint André avec abba Dabba (חІтдпє).

$\mathrm{Au}$ coin sud ouest, une petite chapelle en bois conserve encore les reliques des deux saints Côme, Damien, leur mère et leurs trois frères. Cette chapelle est adossée à une petite porte en bois dépourvue de décor et qui mène au baptistère. Parmi les icônes qui se voient sur la paroi sud

(1) AL-MAQRIZI, Tārīh hu, pp. 160-161.

(2) Ses reliques furent transportées du monastère de la Vierge à al-Qalamūn à l'Église Suspendue de la Vierge au Vieux Caire puis dans une petite chapelle édifiée dans le monastère de saint Bichoï à Wādī Națrūn. Une église lui est construite, plus tard, dans le monastère de saint Macaire le Grand dans la même région. O. F. A. MeInardus, Faith, p. 168, n²2; G. GaBra, Coptic Monasteries. Egypt's Monastic Art and Architecture, with a Historical Overview by T. VIVIAN, Cairo-New York, 2002, pp. 46, 62.

(3) R. BASSET, "Synaxaire", PatrOr., XVII/3, p. 7 baounah/14 juin. 
de l'église, deux comptent parmi les oeuvres de l'icôniste grec Anasthas al-Rūmī comme le confirme les bandeaux épigraphiques inscrits en arabe au-dessous de chaque icône. L'une montre l'archange Michel et l'autre représente la sainte Vierge Marie emportant l'Enfant Jésus. Une troisième icône sur la même paroi montre la crucifixion du Christ. N'oublions pas que les icônes qui représentent sainte Mohraté et qui se trouvent dans cette église sont modernes. Chaque icône la montre dans l'attitude traditionnelle, c'est à dire, elle est debout dans une attitude frontale en tenant une aiguillère dans sa main gauche (pl. III). Dans l'autre, elle tient la croix de la victoire. Un ange ailé lui met la couronne de la vie éternelle sur sa tête auréolée. Vêtue d'une longue robe, Mohraté piètine des serpents, des vipères et des scorpions. Tout près d'elle, et à une échelle beaucoup plus petite, nous voyons son petit frère Abba Ḥor qui est, aussi, montré de face, dans l'attitude de l'orant, en rehaussant ses deux mains. Derrière eux, l'icôniste a dessiné les montagnes de Tura, à l'est du Nil et le bateau des saints martyrs comme c'est mentionné dans la biographie de sainte mohraté.

Al-Qiss Yusūf Tadros al-Ḥūmī qui est actuellement, responsable, du monastère, nous a montrée, durant notre visite au monastère, un

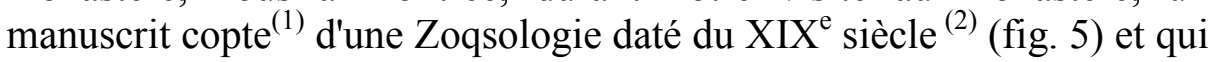
est ridigé en deux langues: le copte bohairique et l'arabe. Dans ce manuscrit qui a été copié d'un autre plus ancien, nous lisons le nom arabe de sainte Muhrā'îl et cette courte phrase arabe: ذكصولوجية واطس لثهادة القديسة مهراييل, à la première ligne d'en haut, dans une des pages de ce manuscrit.

De nos jours, la Messe se déroule, régulièrement, dans le monastère de Manīyal Šịha le vendredi, le dimanche et lors des fêtes religieuses. Notons, aussi, que sa sainteté Pape Chénouté III a tenu une séance scientifique la nuit de l'Épiphanie qui eut lieu le mercredi 19 janvier 1998 avec cinq métropoles et quelques évêques pour affirmer la

(1) Manuscrit copte $n^{\circ} 18$ rite, $\mathrm{XIX}^{\mathrm{e}}$ siècle. Étant auparavant un des manuscrits du patriarcat copte, Émile Māhir (actuellement Père Chénouté) l'a traduit en arabe. Une autre copie identique fut découverte dans le monastère de Manīyal Šịha. Cf. Y. T. AL-HuUM, Sìrat, p. 98, nº127.

(2) Y. T. AL-HuMI, Sīrat, pp. 98-99. 
biographie de sainte Mohraté, son nom, son église et ses fêtes ${ }^{(1)}$. Ajoutons, aussi que son nom est, actuellement, portée par plusieurs Religeuses de l'Église Copte Orthodoxe ${ }^{(2)}$, notamment, dans le monastère de saint George à Ḥārit Zuwaila, celui de saint Théodore à Ḥārit al-Rūmm, les deux monastères de saint George et de saint Mercure au Vieux Caire. On compte, aujourd'hui, à peu près de cent soixante-dix filles coptes nées de 2/11/1985 au 14/2/2000 ${ }^{(3)}$ et qui portent le nom de cette sainte dont la figure est, récemment, publiée dans le journal copte al-Kirāza.

En conclusion, sainte Mohraté, comme plusieurs autres saints et saintes coptes, est souvent absente dans les textes historiques. L'hagiographie égyptienne avec ses textes grecs, coptes et arabes ne nous permet pas d'identifier cette sainte avec exactitude. Il se peut qu'il y ait eu deux saintes coptes connues avec ce même nom. Il est probable que c'est une seule sainte dont le culte était en vogue, en même temps, dans deux endroits différents: au Guizeh et en Haute-Égypte. De son église archéologique originelle, il ne reste plus grande chose. C'est seulement une petite chapelle qui fait partie, aujourd'hui, du monastère des saints Côme et de Damien à Manīyal Šịha. De nos jours, les fêtes de sainte Mohraté et de sa famille sont, annuellement, célébrées quatre jours: le 14 tūba/19 janvier le jour de son martyre, le 22 misrā/28 août le jour de la consécration de son église, le 12 abīb/19 juillet le jour du martyre de son frère Abba Hor et finalement, le mois de tūt/18 septembre qui est le jour de la mort de son père. Nous espérons que d'autres chercheurs mèneront, à la future, des enquêtes qui reprennent et qui poussent en profondeur l'analyse des détails de la vie de cette sainte.

\section{SHERIN SADEK EL-GENDI ${ }^{(\bullet)}$}

(1) Mă̆alat al-Kirāza, V-VI, Le Caire (1998), p. 5, 18; Y. T. AL-Ḥumi, Sīrat, pp. 2627.

(2) Y. T. al-ḤumI, Sìrat, p. 115.

(3) Y. T. al-Humi, Sïrat, pp. 115-120.

${ }^{(\bullet)}$ Professeur-Adjoint d'art et d'archéologie coptes et islamiques. Faculté des Lettres/ Université de 'Ain Shams (l'ÉGYPTE). 


\section{MOHRATÉ UNE SAINTE COPTE OUBLIÉE PAR L'HISTOIRE}

\section{Liste des abbréviations et des périodiques}

BIFAO: Bulletin de l'Institut français d'archéologie orientale. (Le Caire).

BSAC: Bulletin de la société d'archéologie copte. (Le Caire).

ChronEg.: Chronique d'Égypte. Fond. Égyptol. Reine Elisabeth. Cf. CdE. (Bruxelles).

CoptEnc.: Coptic Encyclopedia, 8 vols. (New York).

MPÖN:Mitteilungen aus der Papyrusammlung der österreichischen Nationalbibliothek. (Wien).

PatrOr.: Patrologia Orientalis. (Turnhout/Belgique).

ROC: Revue de l'Orient Chrétien. (Paris).

\section{Bibliographie}

\section{Manuscrits:}

Manuscrit Paris-arabe $n^{\circ} 73$, composé par anbā PHILIPPE évêque de Memphis, Bibliothèque Nationale de la France, IV siècle.

Manuscrit $n^{\circ} 42$ histoire, monastère de saint Paul à la Mer Rouge, homélie de la martyre Muhrā'̄il, composé par anbā PHILIPPE évêque de Memphis, IV ${ }^{\mathrm{e}}$ siècle, f. 71 .

Manuscrit $n^{\circ}$ 93/1a histoire des patriarches de l'église copte de SAWIROS IBN ALMUQAFFA', traduit de l'éthiopien à l'arabe par AKHRUSTOZOLOS ('ABD AL-MASIH), Musée Copte du Caire, XIII ${ }^{\mathrm{e}}$ siècle.

Manuscrit $n^{\circ}$ 102/485 histoire-homélie. Homélie 8. Témoignage d'Abba Yassā et Thècle. Histoire (23 ba'ūna 1266 ère des martyrs/1550).

Manuscrit $n^{\circ} 64$ général (64 saints), ridigé AL-QISS DAWUD à Ḥārit al-Rūmm, monastère de saint Paul (1420 ère des martyrs/1704).

Manuscrit $n^{\circ} 30$ général (30 saints) ridigé par BOUTROS IBN 'ABD AL- MASIḤ, monastère de saint Paul (1429 ère des martyrs/1713), $\mathrm{f}^{\text {os. }}$ 71-126.

Manuscrit $n^{\circ} 220 / 155 a$ rite-synaxaire, au Musée Copte du Caire (1450 ère des martyrs/1734).

Manuscrit $n^{\circ} 77$ histoire (103 ancien), monastère de saint Antoine (1474 ère des martyrs/1758), f ${ }^{\text {os. }} 168-191$.

Manuscrit arabe $n^{\circ} 24$ histoire-homélie, (biographie du saint martyr Abba Hor), église de la Vierge Marie à Ḥārit Zuwaila, au Caire.

Manuscrit $n^{\circ} 122$ histoire, monastère de Mar Mina à Fumm al-Halīğ, au Caire .

Manuscrit $n^{\circ}$ 950/70 rite, patriarcat copte à Ézbékeya (30 bachons 1542 ère des martyrs/1826).

Manuscrit $n^{\circ} 1037 / 69$ rite, ridigé par IBRAHIM ȘALIB, patriarcat copte à Ézbékeya (5 țūba 1627 ère des martyrs/1911). 


\section{MOHRATÉ UNE SAINTE COPTE OUBLIÉE PAR L'HISTOIRE}

Manuscrit $n^{\circ} 741$ histoire, monastère de saint Macaire à la Vallée du Naṭrūn.

Manuscrit de la biographie d'Apater et sa soeur Irānī. Histoire, monastère des Syriens à la Vallée du Națūn, publié par le père ABADIR AL-SURYANI, Le Caire, 1989, f. 33.

Manuscrit $n^{\circ} 28$ général $/ 18$ rite, monastère des martyrs Côme et Damien à Manīyal Šịha au Guizèh.

\section{Références:}

'ABD AL-ḤAlim NuR AL-Din, Mawāqi' wa matāḥif al-ațār al-mișrīya, Le Caire, 1998, (Mawāqi ).

'ABD AL-ḤLIM NUR AL-DIN, al-Luğa al-mișrīya al-qadīma, $\mathrm{V}^{\text {th }}$ ed., Le Caire, 2003,

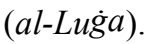

'ABD AL-MASIH ȘALIB AL-MAS'UDI AL-BARAMUSI, Tuḥfat al-sā'ilīn fì dikr adyurat ruhbān al-mișrīȳin, Wādī al-Naṭ̂ūn, 1998, (Tuḥfat).

ABU'L-MAKARIM, SA'DALLAH IBN GUIRGUIS IBN MAS'UD, Tārīḥ al-kanā'is wa'ladyura fì al-qarn al-tānī ašr al-mīlādī, attribué à tort à ABU ȘALIḤ (THE ARMENIAN), II- la Haute-Égypte, la Nubie et l'Afrique, commenté par SAMUEL AL-SIRYANI et NABIH KAMIL DAWUD, Le Caire, 1984, (Tārīh̆).

ABū ȘĀLIH (THE ARMENIAN), the Churches and Monasteries of Egypt and Some Neighbouring Countries Attributed to ABŪ ȘĀLIH (THE ARMENIAN), Translated from the Original Arabic by M. A. B. T. A.EvetTs, with Added Notes by A. J. ButLer, Oxford, 1895, (Churches).

'ALĪ MUBĀRAK, al-Hुițat al-tawfíqīya al-ğadīda limișr al-Qāhira wa mudunihā wabilādihā al-qadīma wa'l-šahīra, XI, Le Caire, s. d., (al-Hițat).

É. AmelineAu, La géographie de l'Égypte copte, Paris, 1893, (Géographie).

É. AmelineAu, Les actes des martyrs de l'église copte-étude critique, Paris, 1890, (Actes).

Art., "Tārīh mā ahmalahu al-tārīḥ. Muhrā'îl-qidīsa min al-qarn al-rābi" ibnat al-itnā 'ašr rabī'an”, al-Yaqaẓa, IV, Le Caire (1996), pp. 31-35, (Tārīhu).

Art. “al-qiddīsa Muhrā’̄il”, Madāris al-aḥād, VII, Le Caire (15 août 1997), pp. 10-11, (al-qiddīsa).

'AZĪZ SuRĪYĀL 'AṬīYA, "Some Egyptian Monasteries According to the Unpublished MS. of al-Shābushtī’s. Kitāb al-Diyārāt”, BSAC, V, Le Caire (1939), pp. 1-7, (Some).

'AZĪZ SurīyĀL 'AȚīYA (Ed.), Coptic Encyclopedia, IV, VI, New York, 1991, (CoptEnc.).

R. BASSET, "Le synaxaire arabe jacobite (rédaction copte)", 1. Les mois de Tout et de Babeh, Texte arabe publié, traduit et annoté par R. BASSET, PatrOr., I, Turnhout/Belgique (1910), pp. 219-279; 2. Les mois de hatour et de kihak", PatrOr., III, (1906), pp. 243-545; 3. Les mois de toubeh et d"amchir", PatrOr., XI/5, (1915), 


\section{MOHRATÉ UNE SAINTE COPTE OUBLIÉE PAR L'HISTOIRE}

pp. 507- 859; 4. Les mois de barmahat, barmoudah et bachons", PatrOr., XVI, (1922), pp. 185-424; 5. Les mois de baounah, abib, mesoré et jours complémentaires", PatrOr., XVII/3, (1923), pp. 525-782, (Synaxaire).

T. BAUMEISTER, Martyr Invictus: Der Martyrer als Sinnbild der Erlösung in der Legende und im Kult der frühen koptischen Kirche zur Kontinuität des ägyptischen Denkens, Forschungen zur Folkskunde 46, Münster, 1972, pp. 123-124.

G. M. Browne, "the Martyrdom of Paese and Thecla (P. Mich. Inv. 548)", ChronEg., IXL, Bruxelles (1974), pp. 201-205, (Martyrdom).

M. G. DARESSY, "Indicateur topographique du Livre des Perles enfouies et du mystère précieux”, BIFAO, XIII, Le Caire (1917), pp. 175-230, (Indicateur).

H. Delehaye, Les martyrs d'Égypte, Bruxelles, 1924, (Martyrs)

H. Delehaye, Sanctvs. Essai sur le culte des saints dans l'antiquité, Bruxelles 1927, (Sanctvs).

A. J. Festugiere, Sainte Thècle. Saints Côme et Damien, Saints Cyr et Jean (extraits). Saint Georges, coll. grecques de miracles, Paris, 1971, (Sainte).

G. Gabra, Coptic Monasteries. Egypt's Monastic Art and Architecture, with a Historical Overview by T. VIVIAN, Cairo-New York, 2002, (Monasteries).

H. GAUTHIER, Dictionnaire des noms géographiques contenus dans les textes hiéroglyphiques, 6 vols., Le Caire, 1925-1931, (Dictionnaire).

History of the Patriarchs of the Egyptian Church, Known as the History of the Holy Church, II/3. Christodoulos-Michael (1046-1102 A. D.), traduit et annoté par 'AZIZ SuRIYAL 'AȚIYA, YASSA 'ABD AL-MASIH and O. H. E. KHS. BuRMESTER, Le Caire, 1959, (History of the Patriarchs).

J. HoRN, Studien $z u$ den Märtyrern des Nördlichen Oberägypten, I. Märtyrerverehrung und Märtyrlegende im Werke des Shenute, Beiträge zur Ältesten Ägyptischen Märtyrerüberlieferung, Coll. Göttinger Orientforschungen 4. Reihe: Ägypten, Band 15, Wiesbaden, 1986; II. Märtyrer und Heilige des XI. Bis XIV. Oberägyptischen Gaues. Ein Beitrag zur Topographia Christiana Ägyptens, Wiesbaden, 1992, (Studien).

H. HYVERNAT, Les actes des martyrs de l'Égypte tirés des manuscrits coptes de la bibliothèque Vaticane et du Musée Borgia. Texte copte et traduction française avec introduction et commentaires par H. HYVERNAT, I, Paris, 1886, (Actes).

IBN MAMMATI, Qawānīn al-dawāwīn, réalisé par 'AZIZ SURIYAL 'AṬIYA, Le Caire 1943, (Qawānīn).

IBRĀHĪM ȘABRĪ, "Dair Ṭammūh aqdam dair fī al-cālam", Watanī̄, nº1688, Le Caire (mai 1994), p. 9.

Jacut's geographisches Wörterbuch. Herausgegeben von Ferdinand Wüstenfeld, II, Leipzig, 1867, (Jacut's).

De LaCy O'Leary, the Saints of Egypt, Amsterdam, 1937, (Saints). 


\section{MOHRATÉ UNE SAINTE COPTE OUBLIÉE PAR L'HISTOIRE}

L. LeroY, "Les couvents chrétiens", ROC, XI, Paris (1908), p. 43, (Couvents).

Mă̆alat al- Kirāza, V-VI, Le Caire (1998).

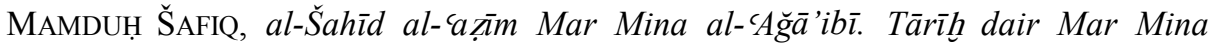
bifumm al-Halīğ, I ${ }^{\text {èr }}$ éd., Le Caire, 2003, (al-Šahīd).

AL-MAQRIZI, TAQIYY AL-DIN AHMAD IBN 'AlI IBN 'ABD AL-QADIR (845/1441), Kitāa al-mawā 'iz wa'l-i 'tibār bidikr al-hițațwa'l-ațār, II, éd. de Būlāq, Le Caire, 1853, (alHitat).

AL-MAQRIZI, TAQIYY AL-Din AHMAD IBN 'Ali IBN 'ABD AL-QADIR (845/1441), Tārīh al-aqbāt al-ma 'rūf bi'l-qawl al-ibrīzì li'l- 'allāma AL-MAQRIZI, commenté par 'ABD AL-MAGID DIYYAB, Le Caire, 1998, (Tārīhu).

O. F. A. Meinardus, Christians in Egypt: Orthodox, Catholic and Protestant Communities. Past and Present, Cairo, 2006, (Christians).

O. F. A. Meinardus, Christian Egypt. Faith and Life, Cairo, 1970, (Faith).


Le Caire, 2000, (al-Qidīsa).


mişrīyyìn ilā sanat 1945, I-III, Cairo, 1953-1954, 1960, 1994, (al-Qāmūs).

NABIL SALIM, Abțāl mağhūlūn, coll. "Min diyārat al-abā' ", no 11, Le Caire, 1970, $(A b t a \bar{l} l)$.

NAS'At ZuQLuma, al-Qidīsa Muhrā'tĭl 'arūs al-șa ‘ìd, Le Caire, 2003, (al-Qidīsa).

T. ORLANDI, Koptische Papyri theologischen Inhalts. Hrsg. Und in das italianisches Übersetzt. (MPÖN S. 9), Wien (1974), pp. 149-154 ("Martirio di Te red Erai"), (Koptische).

A. PAPACONSTANTINOU, Le culte des saints en Égypte des Byzantins aux Abbassides. L'apport des inscriptions et des papyrus grecs et coptes, Paris, 2001, (Culte).

I Papyri Copti del Museo Egizio di Torino, Trascritti e tradotti da F. Rossi, I/5, Torino 1887, pp. 3-8, 32-41, (Papyri Copti)=F. RossI (ed.), I Martirii di Gioore, Heraie, Epimaco e Ptolomeco con altri Frammenti, Memorie della R. Accademia delle Scienze di Torino Ser. 2, XXXVIII, Torino, 1888, pp. 233-308 [262-271], (I Papyri Copti).

al-Qidīsa al-šahīda Maharātī šahīdat madīnat Ṭimāa-Ṭamāw bisūhāğg, I ìre éd., Le Caire, 1998, (al-Qidīsa).

E. A. E. ReYMOND and J. W. B. BARns, Four Martyrdoms from the Pierpont Morgan Coptic Codices, Oxford, 1973, pp. 31-79, (Four).

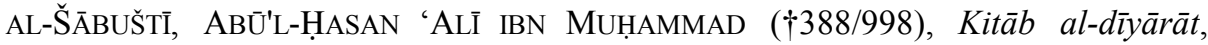
publié par 'AZ̄̄Z SŪRĪYĀL 'AȚīYA, Le Caire, 1939 et plus tard publié par KURKIS 'AWĀḍ, Bag̉dād, 1951, (al-Dìyārāt). 
G. SALMON, "Répertoire géographique de la province du Fayyūm d'après le kitāb tārī al-Fayyūm d'al-Nabulsî”, BIFAO, I, Le Caire (1901), pp. 28-77, (Répertoire).

G. VIAUD, Les pèlerinages coptes en Égypte, d'après les notes du Qommos J. MUYSER, Le Caire, 1979, (Pèlerinages).

YAQUT AL-HaMAWI (VII ${ }^{\mathrm{e}} / \mathrm{XIII}^{\mathrm{e}}$ siècle), Kitāb mu' '̆am al-buldān, II, Beirūt, 1906, (Mu'̆gam).


Caire, 1997, (Mu' '̆gizāt).

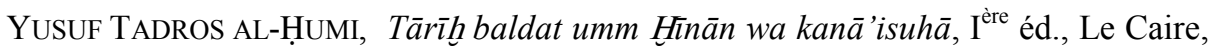
1998, (Tärīhu).

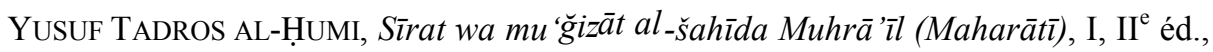
revisé par ANBA BICHOÏ, Le Caire, 2000, (Sìrat).

G. D. ZOËGA, Catalogus Codicum Copticorum Manu Scriptorum qui in Museo Borgiano Velitris Adservantur, Roma, 1810, (Catalogus). 


\section{Figures}

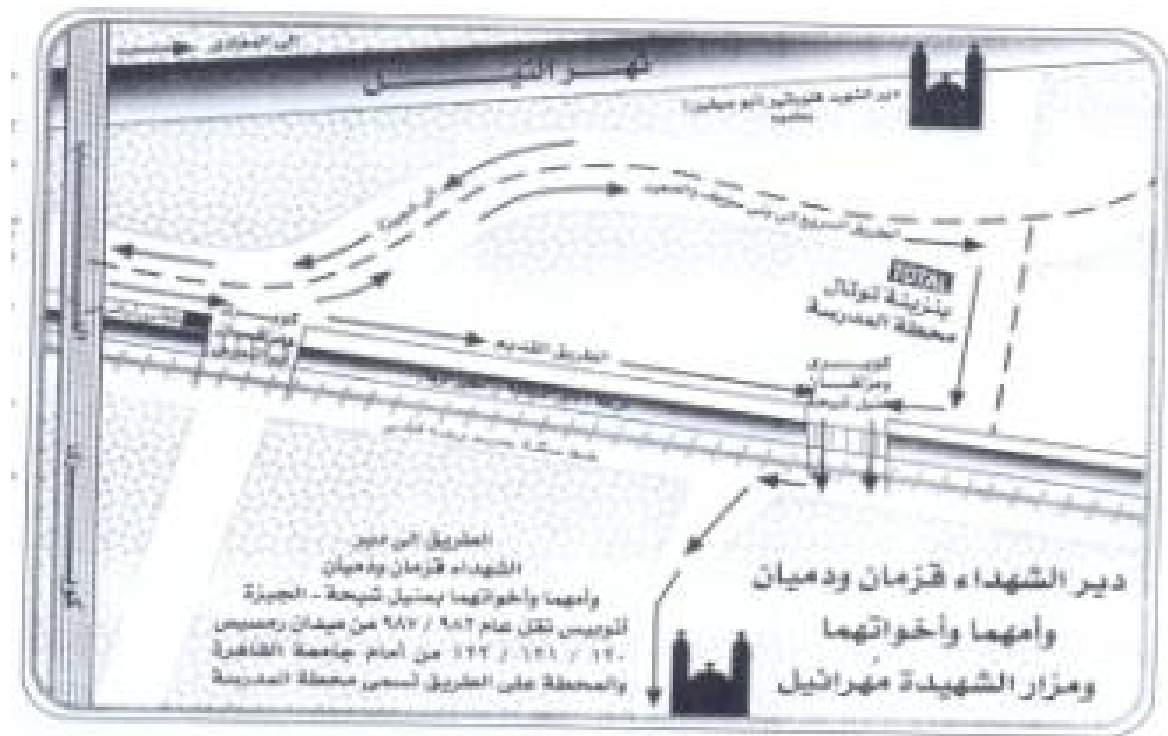

Plan montrant l'endroit où se trouve le monastère des saints Côme et Damien à Manīyal Šīha au Guizèh

Fig. 1


La mention d'ABU'L-MAKARIM, Tārīḥ, II, pp. 120-123.

Figs. 2/a-b 


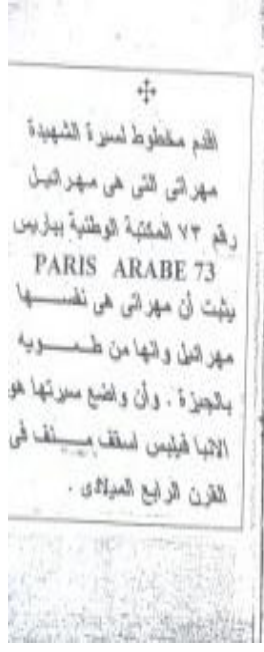

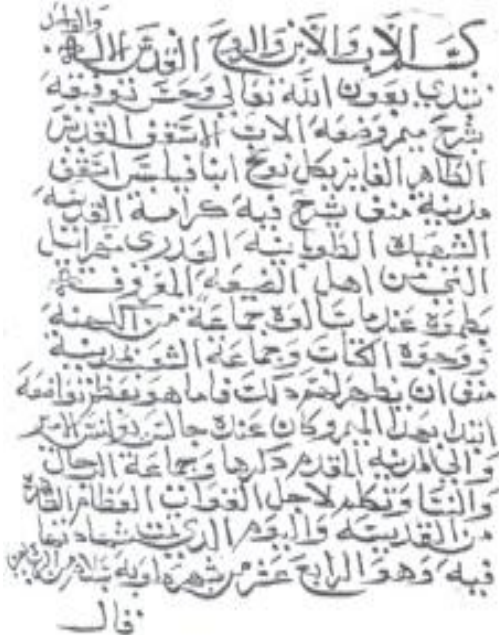

Manuscrit $n^{\circ} 42$ histoire, f. 71

Manuscrit Paris-Arabe $n^{\circ} 73$, f. 1.

Fig. 4

Fig. 3

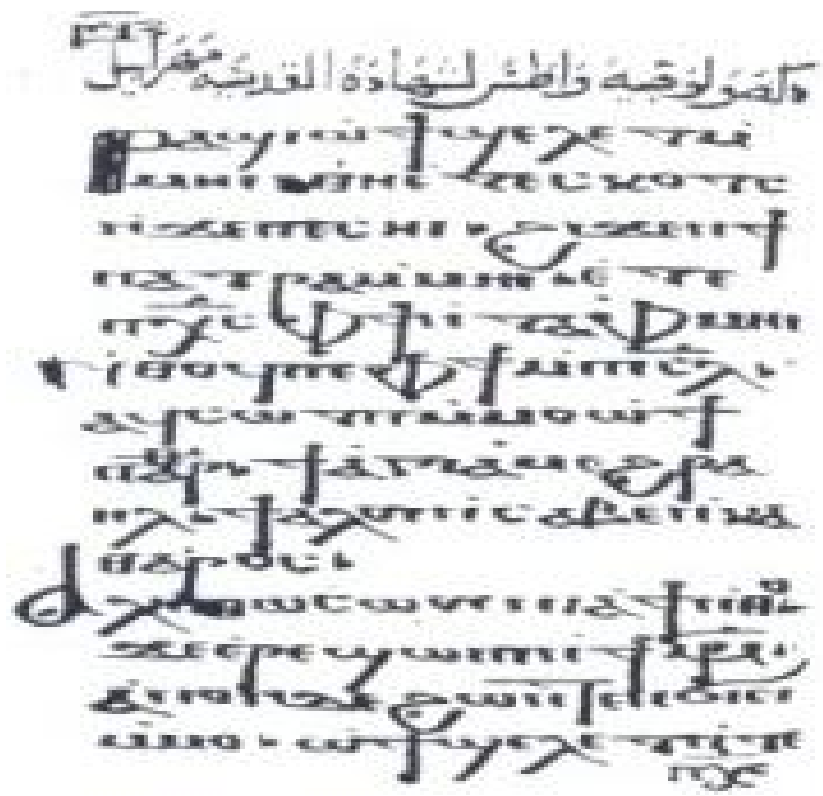

Copie du manuscrit copte $n^{\circ} 28$ général/18 rite de la Zoqsologie Wats de la martyre Mohraté 
Fig. 5

Planches

Pl. I

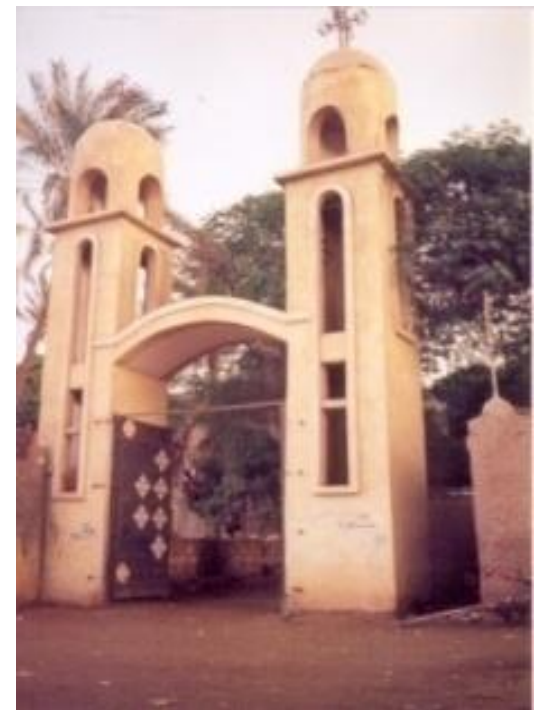

Entrée principale du monastère des saints Côme et Damien à Manīyal Šịha au Guizèh

Pl. II

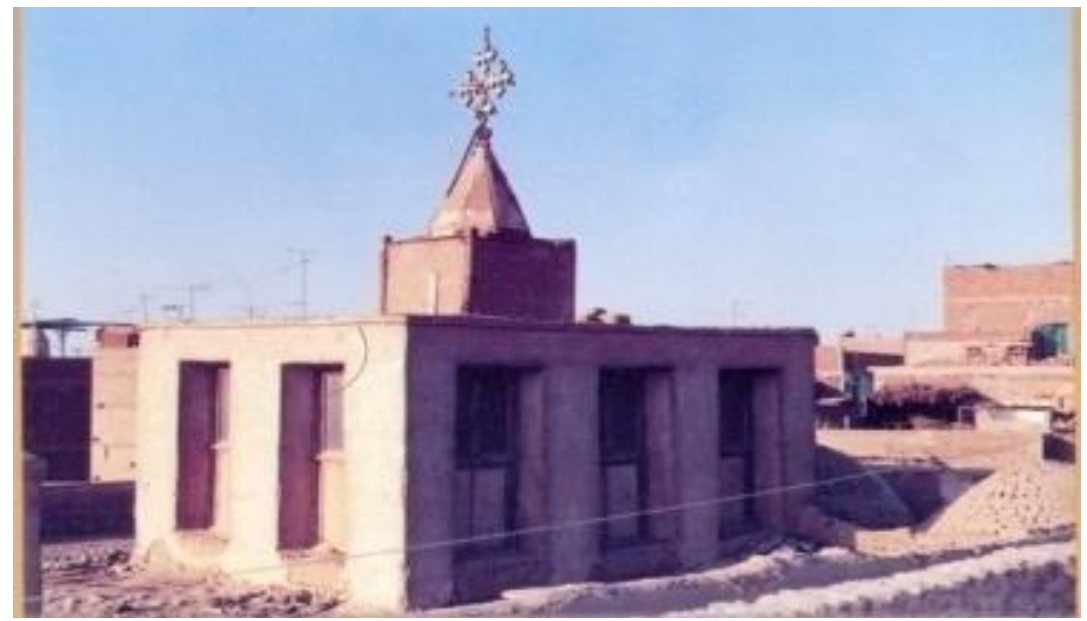

Église attribuée à la sainte Mohraté à Ṭamā en Haute-Égypte.

D'après al-Qidīsa, p. 8. 
PI. III

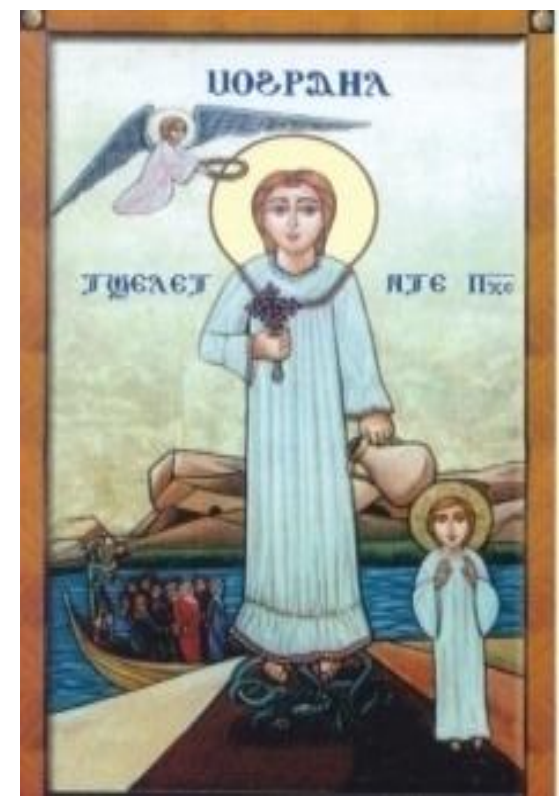

Icône moderne de sainte Mohraté. Monastère des saints Côme et Damien à Manīyal Šịha au Guizèh

\section{Origine des illustrations}

Les illustrations C le Jeudi 05/11/2006. SHERIN SADEK EL-GENDI au monastère des saints Côme et Damien, à Manīyal Šị ḥa, au Guizèh. Sauf pour pl. III (d'après $a l$ Qidīsa, p. 8). 